\title{
Stress response and microstructural evolution of nickel-based superalloys during low cycle fatigue: physics-based modelling of cyclic hardening and softening
}

\author{
F. D. León-Cázares ${ }^{\mathrm{a}, *}$, F. Monni ${ }^{\mathrm{a}}$, T. Jackson ${ }^{\mathrm{b}}$, E. I. Galindo-Nava ${ }^{\mathrm{a}}$, C. M. F. Rae ${ }^{\mathrm{a}}$ \\ ${ }^{a}$ Department of Materials Science and Metallurgy, University of Cambridge, 27 Charles Babbage Rd, Cambridge CB3 OFS, \\ $U K$ \\ ${ }^{b}$ Rolls-Royce plc., Derby DE24 8BJ, UK
}

\begin{abstract}
Low cycle fatigue is one of the main life limiting factors in gas turbine discs. The plastic deformation behaviour that leads to crack initiation is not fully understood, and phenomenological descriptions fail to explain the stress response typical of nickel-based superalloys, which consists of cyclic hardening followed by cyclic softening. In this study, samples of nickel-based superalloy 718 Plus with different ageing heat treatments are fatigued for 500 cycles at room temperature, their microstructures characterised and their slip localisation behaviour quantified via electron channeling contrast imaging (ECCI). A physics-based mesoscopic model is developed to investigate the effects of ageing and loading conditions on cyclic deformation behaviour. The formation of slip bands and evolution of the local dislocation density are used to describe cyclic hardening, while continued precipitate shearing from the accumulation of slip irreversibilities is modelled as the source of cyclic softening. Both mechanisms are then coupled via a parameter for the volume fraction of slip bands. The model successfully reproduces the trends observed for the different conditions, with overaged samples eventually surpassing the cyclic stress of the peak-aged specimens due to a slower softening rate. Curves from the literature for superalloy Nimonic PE16 are also reproduced for different ageing conditions and strain amplitudes. Further electron microscopy near surface cracks reveals the presence of precipitate-free deformation bands only in the underaged condition, which is explained in terms of a saturation point for the shearing process.
\end{abstract}

Keywords: Plastic deformation; Cyclic stress-strain curve; Slip band; Low cycle fatigue; Ni-based superalloys

\section{Introduction}

Over the last fifty years a wide variety of studies have explored the low cycle fatigue (LCF) behaviour of nickel-based superalloys. However, the priority in the scientific community has been to understand the crack initiation and propagation phenomena, rather than the physics of the cyclic deformation process and the evolution of the macroscopic stress-strain response. Whilst this is understandable from a technological perspective, addressing all these phenomena and the links between them is required to guide the development of structural alloys for fatigue applications.

The cyclic stress-strain curves obtained from different tests vary a lot and trends are not easy to identify. To address this issue, a summary of multiple studies is presented in Tables 11 and 2 for solid solution and $\gamma^{\prime}$-strengthened alloys, respectively. This includes tests performed from room temperature to about $800^{\circ} \mathrm{C}$ to capture the transition between different deformation regimes. Higher temperatures are not considered as they have mostly been done in single crystal alloys, which lie beyond the scope of the present work.

*Corresponding author. Email: fdl22@cam.ac.uk 
Table 1: Microstructure and operation conditions of fatigue tests in solid solution nickel-based superalloys where the cyclic stress response is reported. Values in italic are the changing variables in the corresponding work.

\begin{tabular}{|c|c|c|c|c|c|c|c|}
\hline \multirow[t]{2}{*}{ Alloy } & \multirow{2}{*}{$\begin{array}{c}\text { Grain size } \\
{[\mu \mathrm{m}]}\end{array}$} & \multirow{2}{*}{$\begin{array}{c}\text { Temperature } \\
{\left[{ }^{\circ} \mathrm{C}\right]}\end{array}$} & \multicolumn{2}{|c|}{ Strain rate } & \multirow[t]{2}{*}{ Strain ratio } & \multirow{2}{*}{$\begin{array}{c}\text { Strain amplitude } \\
{[\%]}\end{array}$} & \multirow[t]{2}{*}{ Ref. } \\
\hline & & & $\begin{array}{c}\text { Linear } \\
{[\% / \mathrm{s}]}\end{array}$ & $\begin{array}{c}\text { Sinusoid } \\
{[\mathrm{Hz}]}\end{array}$ & & & \\
\hline Alloy 690 & 53 & $R T, 204$ & & 0.15 & -1 & $0.2-0.5$ & (Chai et al. 2004 \\
\hline Haynes HR-120 & - & $R T-982$ & 0.4 & & -1 & $0.2-1.15$ & He et al. 2002 \\
\hline Hastelloy X & 77 & $R T-704$ & 0.04 & & -1 & 0.3 & Miner and Castelli, 1992 \\
\hline Haynes 230 & 60 & $R T-982$ & & $0.003-0.33$ & $-1,0$ & $0.15-0.8$ & (Barrett et al., 2016) \\
\hline
\end{tabular}

RT: Room temperature

Table 2: Microstructure and operation conditions of fatigue tests in $\gamma^{\prime}$-strengthened nickel-based superalloys where the cyclic stress response is reported. Values in italic are the changing variables in the corresponding work.

\begin{tabular}{|c|c|c|c|c|c|c|c|c|c|c|}
\hline \multirow[t]{2}{*}{ Alloy } & \multirow{2}{*}{$\begin{array}{c}\text { Grain size } \\
\quad[\mu \mathrm{m}]\end{array}$} & \multicolumn{2}{|l|}{$\gamma^{\prime}$ precipitate } & \multirow{2}{*}{$\begin{array}{c}\text { Temperature } \\
{\left[{ }^{\circ} \mathrm{C}\right]}\end{array}$} & \multicolumn{2}{|c|}{ Strain rate } & \multirow{2}{*}{$\begin{array}{c}\text { Strain } \\
\text { ratio }\end{array}$} & \multicolumn{2}{|c|}{ Strain amplitude } & \multirow[t]{2}{*}{ Ref. } \\
\hline & & $\begin{array}{l}\text { Size } \\
{[\mathrm{nm}]}\end{array}$ & $\begin{array}{c}\text { Fraction } \\
{[\%]}\end{array}$ & & $\begin{array}{l}\text { Linear } \\
{[\% / s]}\end{array}$ & $\begin{array}{c}\text { Sinusoid } \\
{[\mathrm{Hz}]}\end{array}$ & & $\begin{array}{l}\text { Total } \\
{[\%]}\end{array}$ & $\begin{array}{c}\text { Plastic } \\
{[\%]}\end{array}$ & \\
\hline${ }^{*}$ Experimental alloy & -2 & - & - & 650 & & 0.5 & -1 & $0.3-0.8$ & & Zhang et al. 2015 \\
\hline Mar-M247LC & - & 500 & - & $760-982$ & & 0.05 & -1 & $1.2-1.64$ & & Choe and Lee. I995 \\
\hline Waspaloy & 60 & $\begin{array}{c}8 \\
25 \\
50 \\
90\end{array}$ & - & RT & - & & -1 & & $0.24-0.83$ & Stoltz and Pmeau, 1978 , \\
\hline Waspaloy & $\begin{array}{c}125 \\
16\end{array}$ & $\begin{array}{c}6.5 \\
B: 300+90\end{array}$ & - & $R T-800$ & & 0.33 & -1 & & $0.075-0.15$ & Lerch et al., 1984, \\
\hline Nimonic $80 \mathrm{~A}$ & 60 & $\begin{array}{c}<5 \\
13 \\
20 \\
B: 100+13\end{array}$ & - & RT & & 0.2 & -1 & & $0.025-3$ & Lerch and Gerold, 1987, \\
\hline Nimonic 90 & 300 & - & - & RT & 0.3 & & -1 & $0.4-1.1$ & & Ganesh Sundara Raman and Padmanabhan, 1994 \\
\hline Nimonic 90 & 130 & $\begin{array}{c}S \\
11.35 \\
27.15 \\
60.35\end{array}$ & $\begin{array}{c}0 \\
14 \\
14 \\
14\end{array}$ & RT & 0.3 & & -1 & $0.5-1.1$ & & Subramanya sarma et al., 1998, \\
\hline Nimonic PE16 & - & $\begin{array}{l}12.5 \\
21 \\
30\end{array}$ & $\begin{array}{l}14 \\
-\end{array}$ & RT & 0.4 & & -1 & 0.57 & & Sundararaman et al., 1989, \\
\hline Nimonic PE16 & 30 & $\begin{array}{l}10 \\
21 \\
30\end{array}$ & $\begin{array}{l}7 \\
7 \\
7\end{array}$ & RT & 0.4 & & -1 & $0.6,2.6$ & & Singh et al., 1991, \\
\hline Nimonic PE16 & 65 & $\begin{array}{c}S \\
18 \\
35\end{array}$ & $\begin{array}{c}0 \\
11 \\
11\end{array}$ & 650 & 0.3 & & -1 & $0.25-1$ & & Valsan et al., 1992, \\
\hline Nimonic PE16 & 65 & $\begin{array}{c}S \\
18\end{array}$ & $\begin{array}{c}0 \\
11\end{array}$ & $450-650$ & $0.003-3$ & & -1 & 0.6 & & Valsan et al., 1994, \\
\hline $\begin{array}{l}\text { GH4742 } \\
\text { GH4145/SQ }\end{array}$ & - & B: $80+20$ & - & $\begin{array}{l}650 \\
538\end{array}$ & $\begin{array}{c}0.6-1.4 \\
0.4\end{array}$ & & $\begin{array}{l}-1 \\
-1\end{array}$ & $\begin{array}{c}0.3-0.7 \\
0.35-0.95\end{array}$ & & \begin{tabular}{|l|l|} 
Qin et al. 2015 \\
Ye et al. \\
2004
\end{tabular} \\
\hline Inconel $792-5 \mathrm{~A}$ & 3000 & B: $600+200$ & - & $R T, 900$ & 0.2 & & -1 & $0.16-1.2$ & & Oortlik et al.. zun 9 \\
\hline Udimet $720 \mathrm{Li}$ & 11 & $\mathrm{~T}: 5500+120+50$ & $18,-,-$ & $R T-650$ & 0.5 & & -1 & $0.4-1.2$ & & Gopmath et al. 2009 \\
\hline TMW-4M3 & 8.7 & $\mathrm{~T}: 1500+65+7$ & $16.9,-,-$ & $400-725$ & $0.8-1.2$ & & 0 & $0.4-0.6$ & & Zhong et al, 2012 \\
\hline
\end{tabular}

Difficulties arise when comparing fatigue data from the literature, e.g. microstructures not being fully characterised. Furthermore, as seen in Tables 1 and 2, some of the tests have been done under different loading modes; for instance, using a constant total or plastic strain amplitude control. Similarly, some experiments are performed with a constant strain rate and others with a sinusoidal wave. These differences may introduce variations in the operating deformation mechanisms at different stages of the tests.

The most common behaviour seen in these alloys consists of a short cyclic hardening stage of around 20 cycles followed by softening until crack initiation. This is very different from other fcc materials, which typically show cyclic hardening until stress saturation (e.g. pure copper (Basinski and Basinski, 1992, Lukáš and Kunz, 2004), brass (Henkel et al., 2010), mild steel (Yang and Zhou, 1994) and structural carbon steel (Nip et al. 2010) ) or only cyclic softening (e.g. $\gamma^{\prime \prime}$-strengthened superalloy Inconel 718 (Xiao et al. 2005, 2008; Banerjee et al. 2016; Krishna et al., 2010)). Other materials that show the aforementioned hardening/softening behaviour are alloying systems with coherent shearable precipitates, such as Al-Cu (Lee et al., 1981), Cu-Co (Mughrabi, 1983), Al-Zn-Mg (Vogel et al., 1982). 
Many mechanisms have been proposed to explain the observed responses, but no consensus has been reached regarding which one dominates for each condition. The stress hardening mechanisms that have been mentioned are:

- accumulation of dislocations (Pineau and Antolovich, 2009);

- dynamic strain ageing (Chai et al. 2004, Gopinath et al., 2009, Zhong et al., 2012);

- carbide precipitation on dislocations (He et al. 2002, Antolovich, 2015);

- growth of underaged precipitates (Pineau and Antolovich, 2009).

Alternatively, mechanisms responsible for the cyclic softening include:

- precipitate shearing (Sundararaman et al., 1989, Risbet et al., 2001, Humphreys and Hatherly, 2004, Phillips et al., 2013);

- precipitate disordering (Calabrese and Laird, 1974, Lee et al., 1981; Sundararaman et al., 1989);

- precipitate dissolution (Brechet et al., 1987, Sundararaman et al., 1989, Zhang et al., 2019);

- formation of precipitate-free deformation bands (Stoltz and Pineau, 1978, Sundararaman et al. 1990. Zhang et al. 2015);

- loss of coherency between the matrix and the precipitates (Antolovich et al. 1981);

- formation of planar dislocation structures from a more homogeneous deformation behaviour (Turner, 1979 , Srinivasan et al., 1991);

- growth of overaged precipitates (Antolovich et al. 1981);

- growth of carbides at high temperatures (He et al., 2002);

- grain growth during cyclic loading at high temperatures for long times (Zhang et al., 2015).

It is generally agreed that hardening of the materials is due to dislocation interactions between them or with other microstructural features. In nickel-based superalloys and other low stacking fault energy materials, this occurs in the form of slip bands. These are complex dislocation structures that develop along nearby parallel $\{111\}$ planes connected via a double cross slip mechanism (Wang et al., 2008), where the plastic strain is highly localisedand the formation of point defects, dislocation debris, prismatic loops, dipoles and multipoles hinder the mobility of dislocations (Li and Laird, 1994, Lukáš and Kunz, 2004, Déprés et al. 2004: Risbet and Feaugas, 2008, Ho et al., 2015). Slip bands in superalloys start forming from the initial fatigue stages. In tests with a high strain amplitude these form during the first cycle (Petrenec et al. 2014 , Mello et al. 2017), whereas they may develop gradually over multiple cycles for lower amplitudes (Risbet et al. 2003; León-Cázares et al., 2020). As the fatigue process continues, the dislocation density within the bands is expected to increase until a balance between their generation and annihilation is reached. The morphology and distribution of slip bands at the saturation point varies considerably with the operating conditions (Valsan et al., 1994) and the microstructure of the material (Singh et al., 1991; Sundararaman et al., 1990; Ho et al., 2015).

Solid solution superalloys present cyclic softening, although typically with lower rates than materials that contain precipitates. Softening in solutionised materials may occur due to a transition in the deformation behaviour, from a homogeneous distribution of slip towards a more localised planar dislocation structure (Pham et al., 2011, 2013).

The higher softening rates in $\gamma^{\prime}$-reinforced superalloys have been mostly associated to the first three mechanisms in the aforesaid list: precipitate shearing, disordering and dissolution, although there is controversy regarding which one dominates. All these processes soften the material by effectively decreasing the 
precipitate cross sectional area that the dislocations have to traverse, but they differ in the kinetics driving this change.

Gradual shearing of the precipitates during cyclic deformation occurs due to the to-and-fro glide of dislocations in the matrix and dislocation pairs within the precipitates Yashiro et al. $(2006)$; Huang et al. (2012). The average shear step length increases as the cyclic test progresses (León-Cázares et al., 2020), resulting in a reduction of the precipitate cross sections. This behaviour arises from slip irreversibilities, by which dislocations glide in one direction but are unable to glide back. Examples of these events are cross slip, dislocation annihilation, trapping in the form of dipoles and emergence of dislocations at a crystal surface, among others (Mughrabi, 2009, 2013a b).

In some fatigue tests, deformation bands with no precipitates have been reported; however, their formation mechanisms and conditions for their occurrence are not yet fully clear. Superalloys in which they have been identified include Waspaloy (Stoltz and Pineau, 1978), Nimonic PE16 (Singh et al., 1991; Sundararaman et al., 1990) and an experimental nickel-based superalloy (Zhang et al., 2015). Precipitates reappear in these bands if subjected to an adequate heat treatment, meaning that the chemical composition of the band does not vary significantly after they form (Köhler et al., 1984; Sundararaman et al., 1990).

These softening mechanisms increase the localisation of slip as precipitates weaken locally, making it easier for dislocations to glide in these regions. Shin and coauthors (Shin et al., 2005, 2007) corroborated this behaviour by modelling the precipitates within a dislocation dynamics framework as a series of barriers to dislocation motion which soften with each dislocation passing through them. However, a systematic study of the precipitate size effect in a Cu-2at\%Co alloy (Mughrabi, 1983) revealed the existence of a saturation stage with a residual stress contribution from the precipitates, meaning that the softening process does not remove all the strength provided by the second phase particles (Mughrabi, 1983). Tests in many nickel-based superalloys have shown a similar behaviour, with a softening rate that decreases with the number of cycles, although a steady stress amplitude is rarely reached due to early crack initiation.

Stress-strain regimes other than the aforementioned hardening/softening behaviour have been observed at different temperatures in a number of superalloys. At intermediate temperatures, from approximately 200 to $600^{\circ} \mathrm{C}$, a higher hardening with no softening is typically observed. This has been linked mostly to dynamic strain ageing, as it is accompanied by serrations in the stress response (Miner and Castelli, 1992 , Chai et al., 2004, Gopinath et al., 2009, Valsan et al., 1994, Zhong et al., 2012). At higher temperatures the trend reverses, cyclic softening reappears and the peak stress shifts towards a smaller number of cycles. It is not clear whether this transition is only linked to the disappearance of dynamic strain ageing or also because of the activation of other mechanisms. Furthermore, at very high temperatures (above $900^{\circ} \mathrm{C}$ ) a constant stress amplitude, sometimes following a slight softening stage, is seen (Obrtlík et al., 2009). This might occur due to a transition towards a more homogeneous deformation with no precipitate shearing, as observed in a number of alloys (He et al. 2002, Gopinath et al., 2009).

There are also clear deviations in behaviour for alloys with large precipitates. Steeper hardening rates and slower softening are characteristic of materials in an overaged condition. This has been associated with the transition towards a more homogeneous deformation behaviour (Singh et al., 1991, Shin et al. 2005). Besides, the storage of Orowan loops is promoted around large precipitates, which results in a higher kinematic hardening (Brown and Stobbs, 1971; Kassner et al., 2008).

Overall, the listed hardening and softening mechanisms related to a change of coherency or growth of precipitates, carbides or grains are very specific to a number of conditions and could not systematically explain the behaviour observed along this range of microstructures and tests. Slip localisation, dislocation accumulation and precipitate degradation are considered the main mechanisms behind the evolution of the stress amplitude during low cycle fatigue in nickel-based superalloys. Therefore, these are explored in more detail throughout this work, whichcombines microstructural characterisation of a superalloy after different ageing times with physics-based modelling of the hardening/softening behaviour. This represents a key step towards understanding the process of damage localisation along slip bands prior to crack initiation. 


\section{Material and Methods}

The material examined in this study is the polycrystalline nickel-based superalloy 718Plus, supplied by Rolls-Royce Deutschland. The composition of this alloy is given in Table 3 . 718Plus was selected due to its slow $\gamma^{\prime}$ precipitation kinetics (Srinivasan et al., 2012), which allow for a solutioning heat treatment followed by rapid cooling to avoid the nose of the TTT diagram and obtain a single phase material.

The initial shape of the material was a slice of supersolvus hammer forged billet with a diameter of 230 $\mathrm{mm}$ and thickness of $56 \mathrm{~mm}$. Electrical discharge machining was used to cut cylinders with a diameter of $11 \mathrm{~mm}$ from the centre of the billet. These were subjected to one of four different heat treatments, denoted solutionised (S), underaged (UA), peak aged (PA) and overaged (OA). The solvus temperatures have been reported to be $967^{\circ} \mathrm{C}$ for $\gamma^{\prime}$ and $1012^{\circ} \mathrm{C}$ for the $\eta / \delta$ precipitates (Casanova et al., 2014). Thus, all heat treatments started with a supersolvus solutioning step at $1020^{\circ} \mathrm{C}$ for two hours followed by water quenching. Following the precipitation and coarsening curves given by Zickler et al. (Zickler et al., 2009) for this alloy, ageing was done at $775^{\circ} \mathrm{C}$ for $10(\mathrm{UA}), 38(\mathrm{PA})$ and $72(\mathrm{OA})$ hours, followed by water quenching. Dog-bone shaped fatigue samples with a gauge length of $13 \mathrm{~mm}$ and diameter of $4.3 \mathrm{~mm}$ were then machined from the specimens, removing the oxide layers formed during the heat treatments.

Table 3: Chemical composition of alloy 718Plus (wt\%) Kennedy 2005.

\begin{tabular}{ccccccccc}
\hline $\mathrm{Ni}$ & $\mathrm{Cr}$ & $\mathrm{Co}$ & $\mathrm{Mo}$ & $\mathrm{W}$ & $\mathrm{Al}$ & $\mathrm{Ti}$ & $\mathrm{Nb}$ & $\mathrm{Fe}$ \\
\hline $\mathrm{bal}$ & 18 & 9.1 & 2.7 & 1 & 1.45 & 0.75 & 5.4 & 9.5 \\
\hline
\end{tabular}

Interrupted fatigue tests were performed at room temperature for 500 cycles in an Instron $8862-100 \mathrm{kN}$ servo hydraulic machine with a clip-on extensometer. A fully reversed triangular strain control was used with an amplitude of $\Delta \epsilon / 2=0.83 \%$ and a constant strain rate of $0.3 \% \mathrm{~s}^{-1}$, starting with a tensile load and ending after a compression stage.

Two samples with a thickness of $4 \mathrm{~mm}$ were cut perpendicular to the loading axis from the middle part of the gauge length for each condition. These were hot mounted in bakelite, ground and polished with diamond suspensions and colloidal silica according to standard procedures. The $\gamma^{\prime}$-etchant described in reference (Preuss et al. 2002$)$ was applied for 20 seconds to one sample from each condition.

Scanning electron microscopy (SEM) was performed in a ZEISS GeminiSEM 300. The secondary electron through-lens detector was used on unetched samples to characterise the $\gamma^{\prime}$ volume fraction and precipitate size distribution with the ImageJ software package by first applying the operations of smooth, threshold regional gradient (Landini et al., 2017) and watershed in micrographs taken at different magnifications for each ageing condition.

This detector was also employed in etched samples to observe shear steps in the precipitates. A methodology introduced in previous study (León-Cázares et al. 2020) was used to measure slip line spacings. This technique determines the orientation of the slip plane with respect to the sample surface from the elliptical markings left in the surface of etched holes. While crack initiation and propagation are outside the scope of this study, the higher plastic strains developed near surface cracks are of particular interest for an analysis on the evolution of the microstructure. Thus, these regions were also imaged.

The circular backscattered electron detector was used to measure the grain size via the circular method intercept following the ASTM standard E112-13 with six circles of $700 \mu \mathrm{m}$ diameter in the unetched samples. Electron channeling contrast imaging (ECCI) was performed in over 20 grains at a low magnification $(<1000 \mathrm{X})$ for each condition to identify differences in the spread of the slip bands.

An estimation of the density of active slip planes from ECCI micrographs is used to calculate the amount of slip each of these accommodates. For simplicity, the quantification of the volume fraction occupied by slip bands is preferred over that of their widths and spacings. However, measuring the slip band volume fraction from the intensity profile along a line perpendicular to the band is very inconsistent. The inhomogeneous distribution of dislocations along a given plane makes two profiles from parallel lines vary considerably even when closely spaced. Contrast changes due to small carbides, embedded polishing media or even the $\gamma^{\prime}$ precipitates also affect these profiles. 
Fast Fourier transform (FFT) filtering is used to circumvent these obstacles. The following analysis was performed in 10 grains from each sample in ECCI micrographs at a 5000X magnification with a resolution of $20 \mathrm{~nm} /$ pixel. Parallel bands produce in a FFT image a perpendicular bright sharp line that goes through the centre, as shown in Figure 1(a) for a crystal with slip bands in two different slip plane orientations. Traces of a horizontal and vertical line appear due to the squared shape of the enclosed region, but these can be ignored. In Figure 1(b), filtering out the lines linked to the active slip plane orientations and performing an inverse fast Fourier transformation (IFFT) results in an image with most of the features of the original micrograph, but without the slip bands. The opposite is done in Figures 1 (c) and (d), filtering out from the FFT image everything but a rectangle of width $\sim 3$ pixels along these lines before applying an IFFT. This eliminates the inhomogeneities that were initially randomly distributed and produces a contrast that changes almost uniquely in the direction perpendicular to the selected plane orientation, making the measurements considerably more consistent. The intensity profiles along the red lines from Figures 1.(c) and (d) are plotted in Figures 1(e) and (f), respectively. The volume fractions of slip bands are measured from the ratio of points with an intensity higher than a set threshold, shown with the dashed lines. This value is manually selected to be below the contrast observed in the bands. Only the primary slip system is considered in this analysis.

Transmission electron microscopy (TEM) was performed in the S sample to determine if small $\gamma^{\prime}$ precipitates were present for this condition. Samples were cut from the gauge length, ground to a P2500 grit and electropolished with a Tenupol-5 at $-5 \pm 1{ }^{\circ} \mathrm{C}$ in a $6 \%$ perchloric acid in methanol solution. Bright field (BF) and scanning TEM (STEM) with a high angle annular dark field (HAADF) detector were performed within a FEI Tecnai Osiris operating at $200 \mathrm{kV}$.

\section{Results}

\subsection{Cyclic stress-strain response}

The initial stress-strain hysteresis curves for the different samples are shown in Figure 2(a). The yield stress shows the expected trend, with the PA condition stronger than the rest. A big difference in plastic strain amplitude between different samples can be seen from the first cycle. This varies from $0.62 \%$ for the $\mathrm{S}$ condition to $\sim 0.43 \%$ for the rest, due to its considerably lower yield stress. This must be taken into account for a comparative analysis between the different conditions.

The evolution of the cyclic stress amplitude from Figure 2(b) shows hardening followed by softening for all the samples. Precipitate shearing cannot be the only mechanism responsible for cyclic softening as this is also observed in the S sample, in agreement with LCF in solid solution alloys (Chai et al., 2004; He et al. 2002, Miner and Castelli, 1992, Barrett et al., 2016). Regardless, shearing might have a considerable effect on it as discussed before. The cyclic behaviours of the UA and PA samples are very similar, reaching the maximum stress after 14 and 9 cycles, respectively. The OA condition hardens during the initial $\sim 240$ cycles and eventually reaches a stress amplitude larger than all the other samples. The softening that follows has the smallest slope among all, but increases towards the end of the test.

\subsection{Microstructure}

The ASTM grain size number of the material analysed is 5.86 (mean planar diameter of $47 \pm 2 \mu \mathrm{m}$ ). Annealing twins are very common throughout all the samples. No sign of $\delta / \eta$ precipitates is observed in any of the heat treated samples, as expected from the solutioning step (Pickering et al., 2012).

The number of precipitates counted and relevant data are summarised in Table 4 for the three ageing conditions. Normalised histograms with the corresponding precipitate sizes are given in Figure 3 , fitted to lognormal probability distributions as done in previous studies (Collins and Stone, 2014, Galindo-Nava, 2015). The mean and standard deviation of the logarithmic values of the distributions are also given in Table 4. Alternatively, BF TEM and HAADF STEM confirmed the absence of $\gamma^{\prime}$ precipitates in the S sample, both in the bulk and close to grain boundaries. 

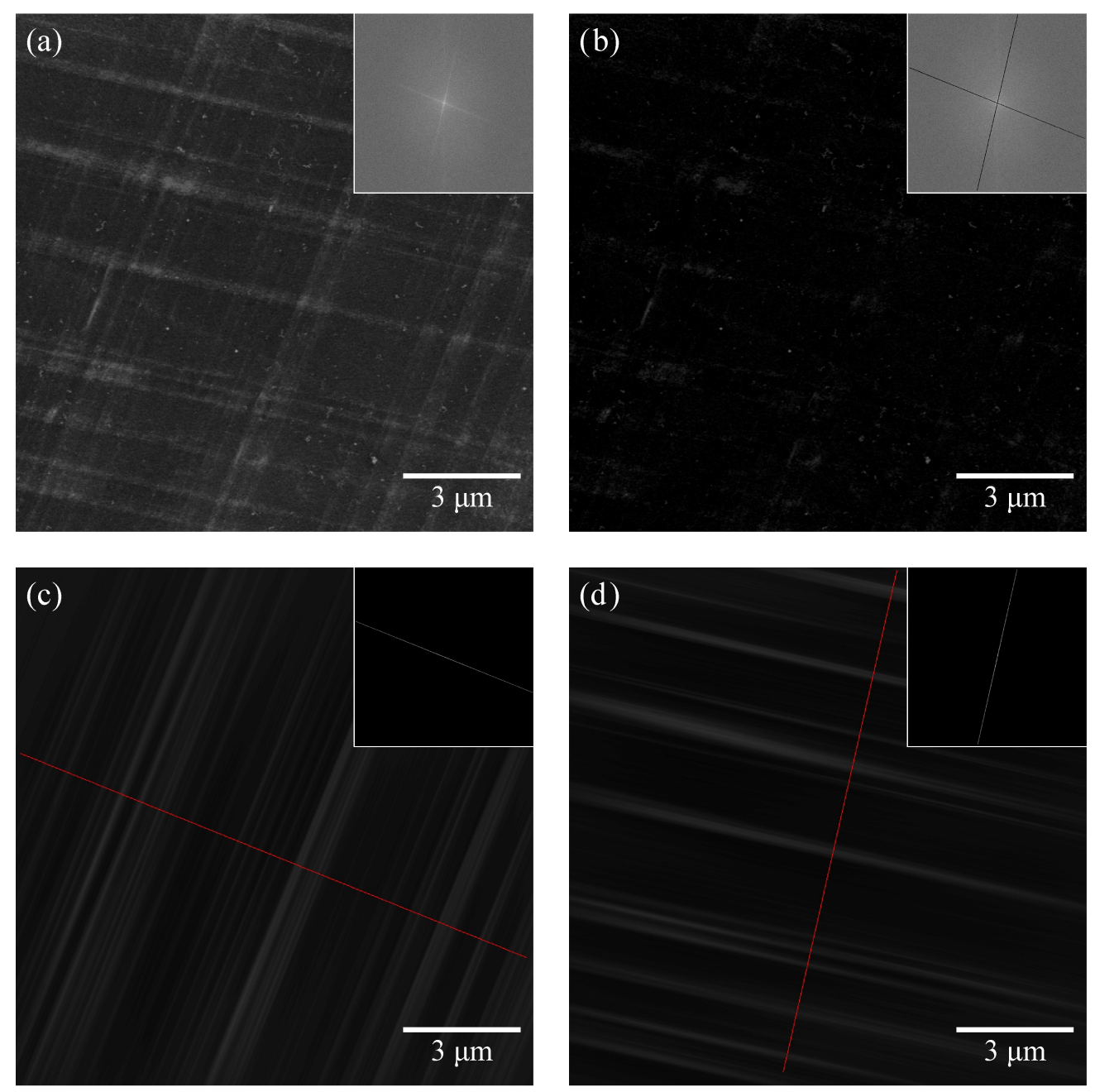

(e)

(f)
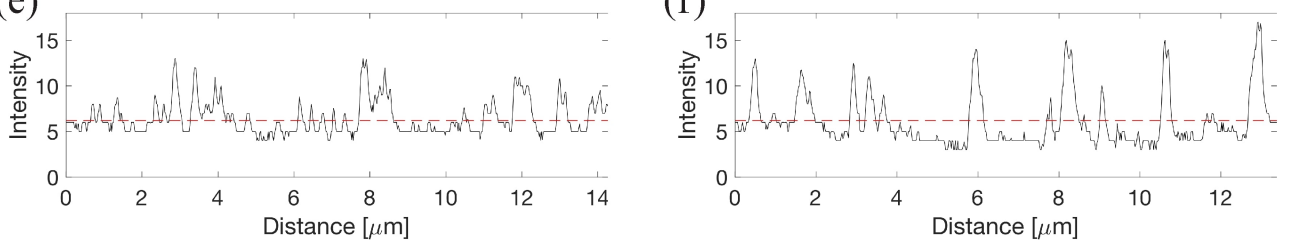

Figure 1: Methodology for the measurement of the slip band volume fractions. (a) Original ECCI micrograph showing a crystal with slip bands in two different orientations. (b) Image produced by filtering out the pixels along the lines with a high contrast from the previous FFT and then applying an IFFT. (c) and (d) result from filtering out from the initial FFT everything but the pixels within a rectangle aligned with a line with high contrast. The intensity profiles along the red lines are shown in (e) and (f), with the selected thresholds shown as dashed lines. All the FFTs are shown in the top right corner of their respective figures, where the black pixels are those filtered out before performing the IFFTs.

\section{3. $E C C I$}

Representative ECCI micrographs for each ageing condition are shown in Figure 4 Plastic deformation is in general accommodated in slip bands that extend through the entirety of a grain; no stacking faults are observed. Multiple slip dominates throughout all samples, with two active slip systems as the most common behaviour. 
(a)

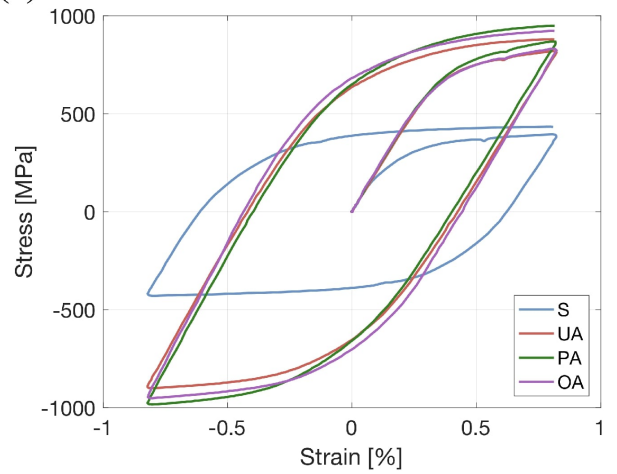

(b)

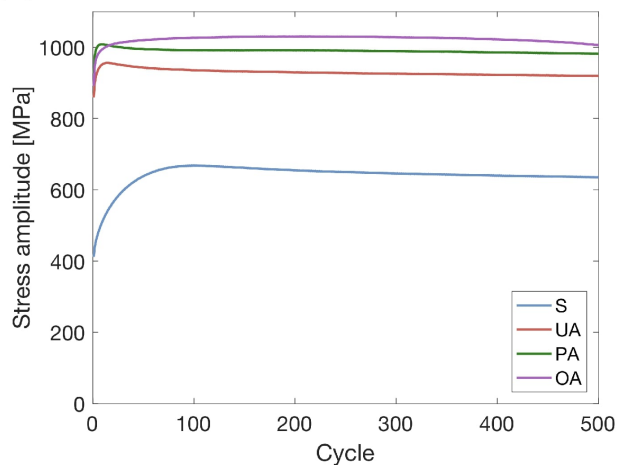

Figure 2: (a) First complete stress-strain hysteresis curve and (b) evolution of the cyclic stress amplitude of the 718Plus samples.

Table 4: $\gamma^{\prime}$ characterisation.

\begin{tabular}{lccccccc}
\hline Sample & Count & Area imaged $\left[\mu \mathrm{m}^{2}\right]$ & Volume fraction [\%] & Mean diameter [nm] & Circularity & \multicolumn{2}{c}{ Lognormal fit } \\
Standard deviation
\end{tabular}

The volume fraction of slip bands in the primary slip system as a function of precipitate size obtained via the FFT filtering is reported in Figure 5. where the large standard deviations highlight the variability observed between grains. The S condition has the highest volume fraction, likely due to the absence of precipitates which have been shown to promote slip localisation (Mughrabi, 1983, Risbet and Feaugas, 2008). Longer ageing times result in a higher fraction of slip bands too. This behaviour agrees with experimental studies on Waspaloy (Ho et al. , 2015) and dislocation dynamics simulations with the incorporation of shearable precipitates (Shin et al. 2005$)$. Note that the difference from the UA to the PA condition is rather small, but a considerable increase is observed for the OA condition.

Some of the grains in the $\mathrm{S}$ condition show a more homogeneous distribution of slip, where parallel bands fill almost the entirety of the volume and slip bands develop in a secondary orientation. This behaviour is also observed to a lesser degree in the OA sample. Examples of this can be seen in Figures 4 (e) and (h). Conversely, all the imaged grains in the UA and PA conditions show localisation of plastic deformation in clearly spaced slip bands.

\subsection{Precipitate shearing}

Signs of precipitate shearing are observed in the three aged microstructures, as shown in Figure 6 in $\gamma^{\prime}$-etched samples. However, there is a large in- and out-of-plane component of the displacement vectors in all the micrographs due to the samples being cut perpendicular to the loading axis. Halves of sheared precipitates are commonly observed because of this. Measurements of the slip line spacings from the holes left in these samples were only obtained in the OA and PA samples, giving an average of $20.1 \mathrm{~nm}$ and 23.8 $\mathrm{nm}$, respectively. The slip bands in the UA sample were spotted but the slip lines could not be traced due to the small precipitate size.

Surface cracks are observed in all samples. Examples of the precipitate morphology in the regions nearby are shown in Figure 7. Clear signs of higher amounts of plastic deformation are observed in all cases. Sheared precipitates populate slip bands in the vicinity of the cracks for the PA and OA conditions. In the former in particular, multiple nearby parallel bands show more shearing than their counterparts in the bulk. In the UA sample, precipitate-free deformation bands appear close to the crack and ahead of the crack tip, 
(a)

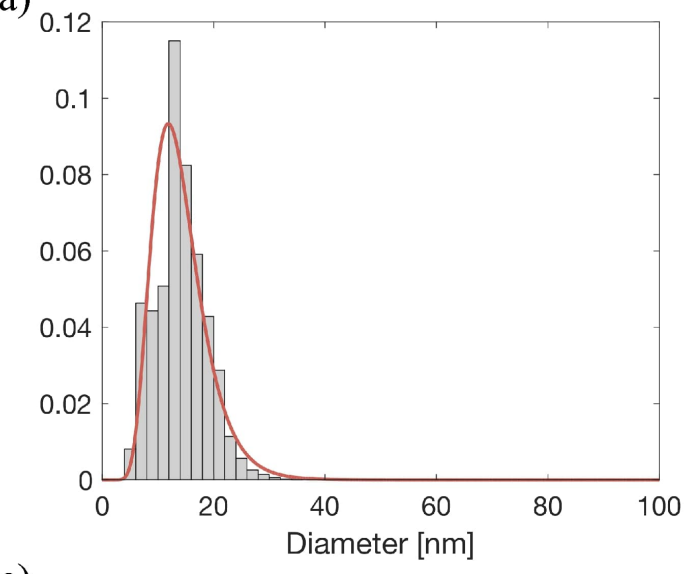

(c)

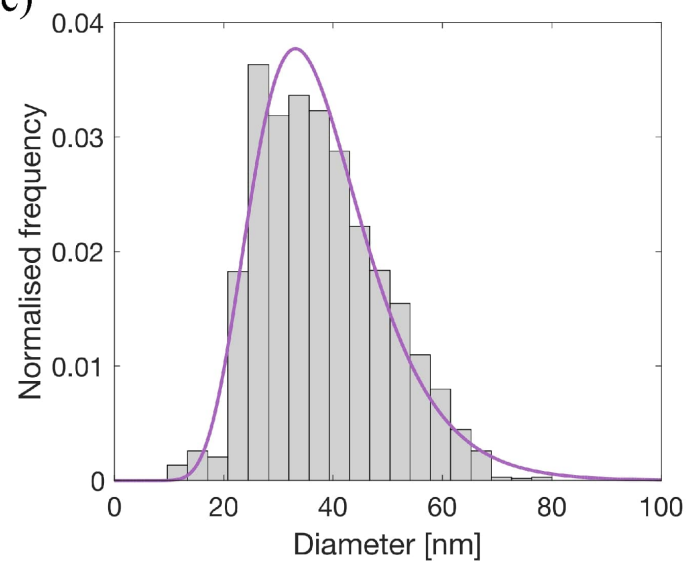

(b)

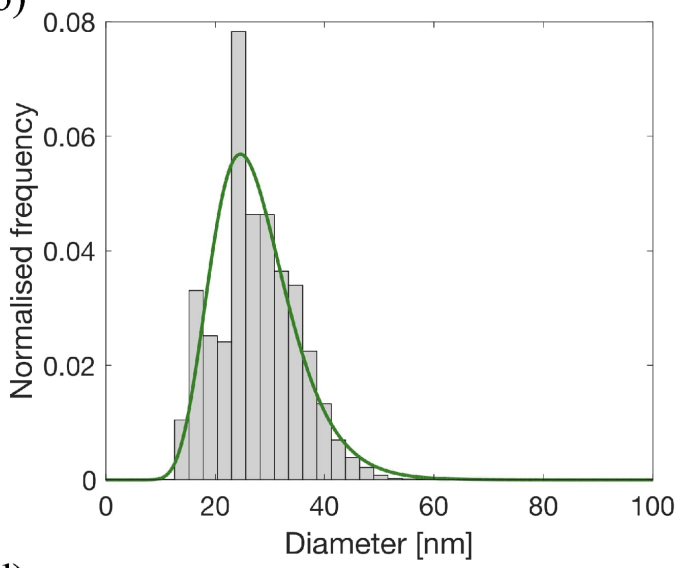

(d)

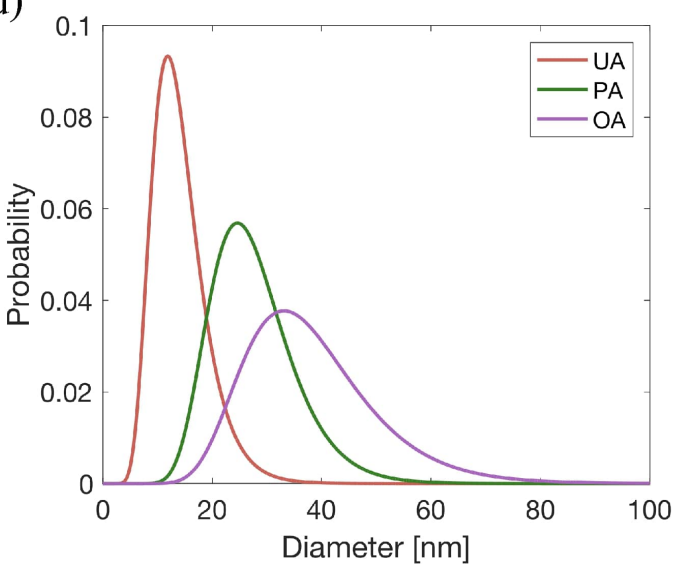

Figure 3: Normalised histograms of the precipitate size in the (a) underaged, (b) peak-aged and (c) overaged samples, fitted to lognormal distributions. These probability distributions are plotted together in (d) for comparison.

hinting towards their dissolution for high cumulative plastic strains. No $\gamma^{\prime}$ is observed in these regions even at higher magnifications.

\section{Modelling}

A mesoscopic model for the cyclic stress-strain response of precipitate-reinforced materials is developed here in light of the experimental results and the trends observed in other nickel-based superalloys. The overall philosophy of this model is that of capturing the functional dependencies of the macroscopic response on microstructural parameters and loading conditions. Precipitate shearing and slip localisation are incorporated to account for the evolution of the microstructure and dislocation structure, while reproducing the hardening and softening behaviours.

\subsection{Cyclic deformation behaviour modelling}

The macroscopic stress $\sigma$ required to drive a certain amount of plastic deformation $\epsilon$ stems from a combination of mechanisms. In this work, the different contributions considered are those of $(i)$ a constant stress $\sigma_{0}$ due to the combined effects of grain boundaries and solid solution (acknowledging that these mechanisms act on very different length scales), (ii) $\gamma^{\prime}$ precipitates $\sigma_{P}$, (iii) isotropic hardening $\sigma_{D}$ due to an increase in the dislocation density which shortens the mean free path of the mobile dislocations, and (iv) kinematic hardening $\sigma_{K}$ from the long-range internal stresses produced by heterogeneous deformation 
S
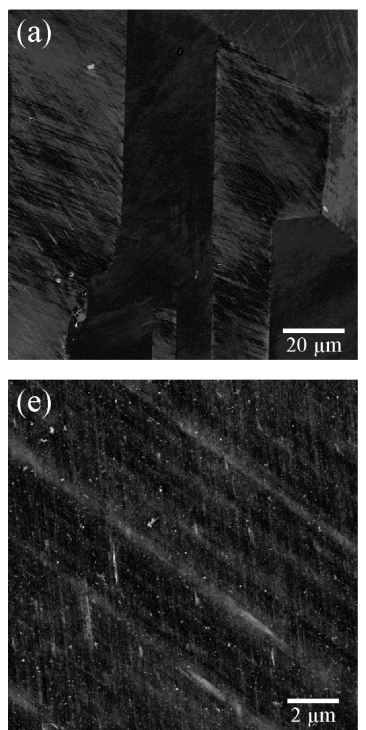

UA
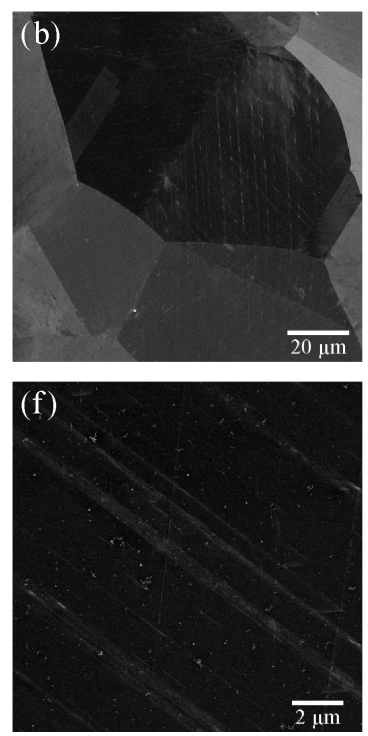

PA
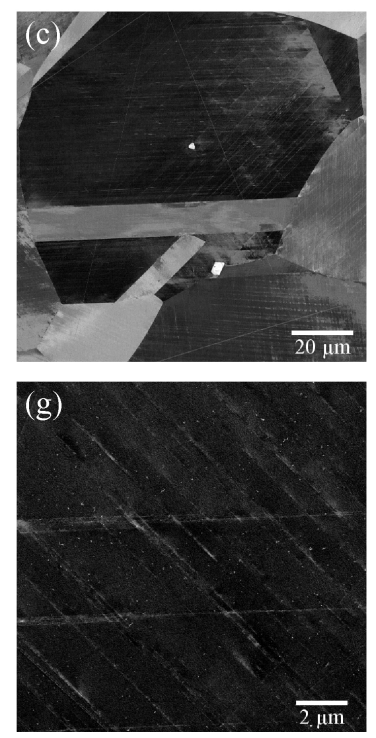

$\mathrm{OA}$
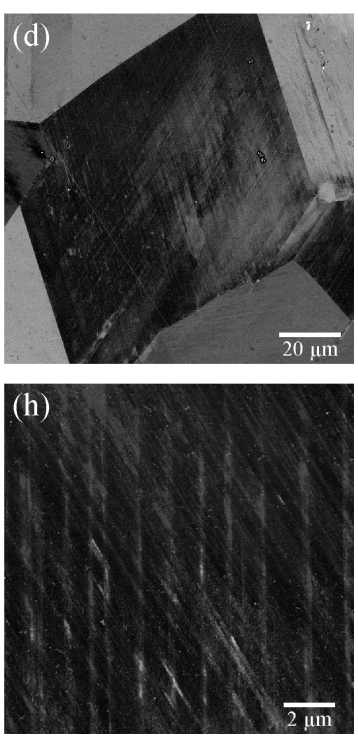

Figure 4: ECCI micrographs of samples from the four ageing conditions at a magnification of (a-d) 600X and (e-f) 5000X.

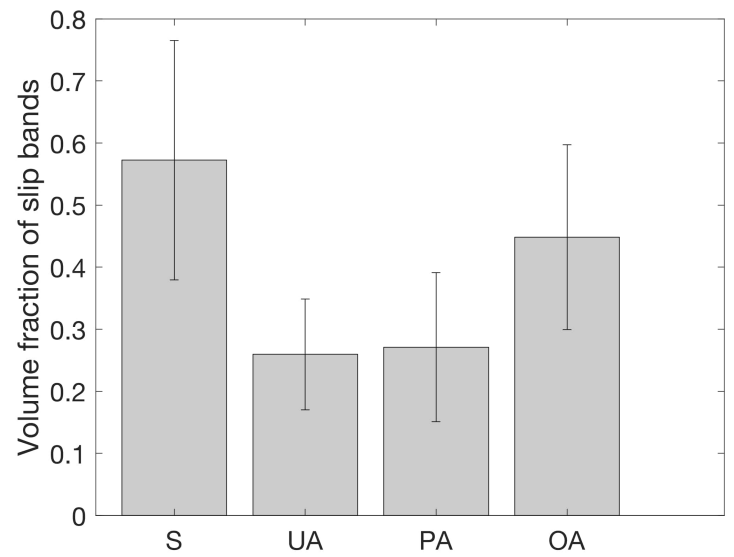

Figure 5: Volume fraction of slip bands in the primary slip system for the different ageing conditions. The error bars denote the standard deviation in the measurements.

(Brown and Clarke, 1975). Congruently with models founds in the literature (Han et al. 2011, Fribourg et al. 2011; Maciejewski and Ghonem, 2014), the superposition of these contributions follows the form

$$
\sigma=\left(\sigma_{0}+\sigma_{P}+\sigma_{D}\right) \cdot \operatorname{sign} \dot{\epsilon}+\sigma_{K}
$$

where sign $\dot{\epsilon}$ denotes the direction of loading ( 1 for tension and -1 for compression). This common simplification in mesoscopic models avoids dealing with stress inhomogeneities that develop from all sorts of constraint effects to focus on the behaviour of the material as a whole, albeit losing detail at shorter length scales. The total strain $\epsilon_{t}=\epsilon_{e}+\epsilon_{p}$ has an elastic $\epsilon_{e}=\sigma / E$ and a plastic $\epsilon_{p}$ components, and the plastic strain rate $\dot{\epsilon_{p}}$ can be further described with Orowan's equation (Orowan, 1940)

$$
\dot{\epsilon_{p}}=M^{-1} b \rho_{m} v
$$



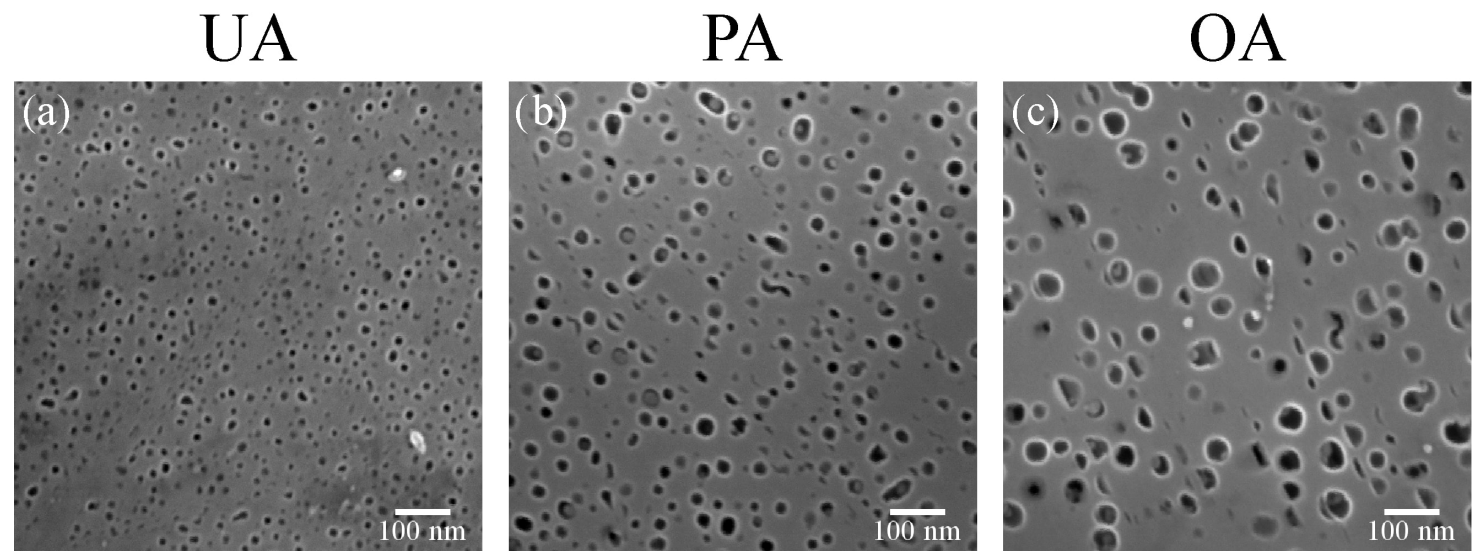

Figure 6: Secondary electron micrographs of slip bands in the (a) UA, (b) PA and (c) OA $\gamma^{\prime}$-etched samples.
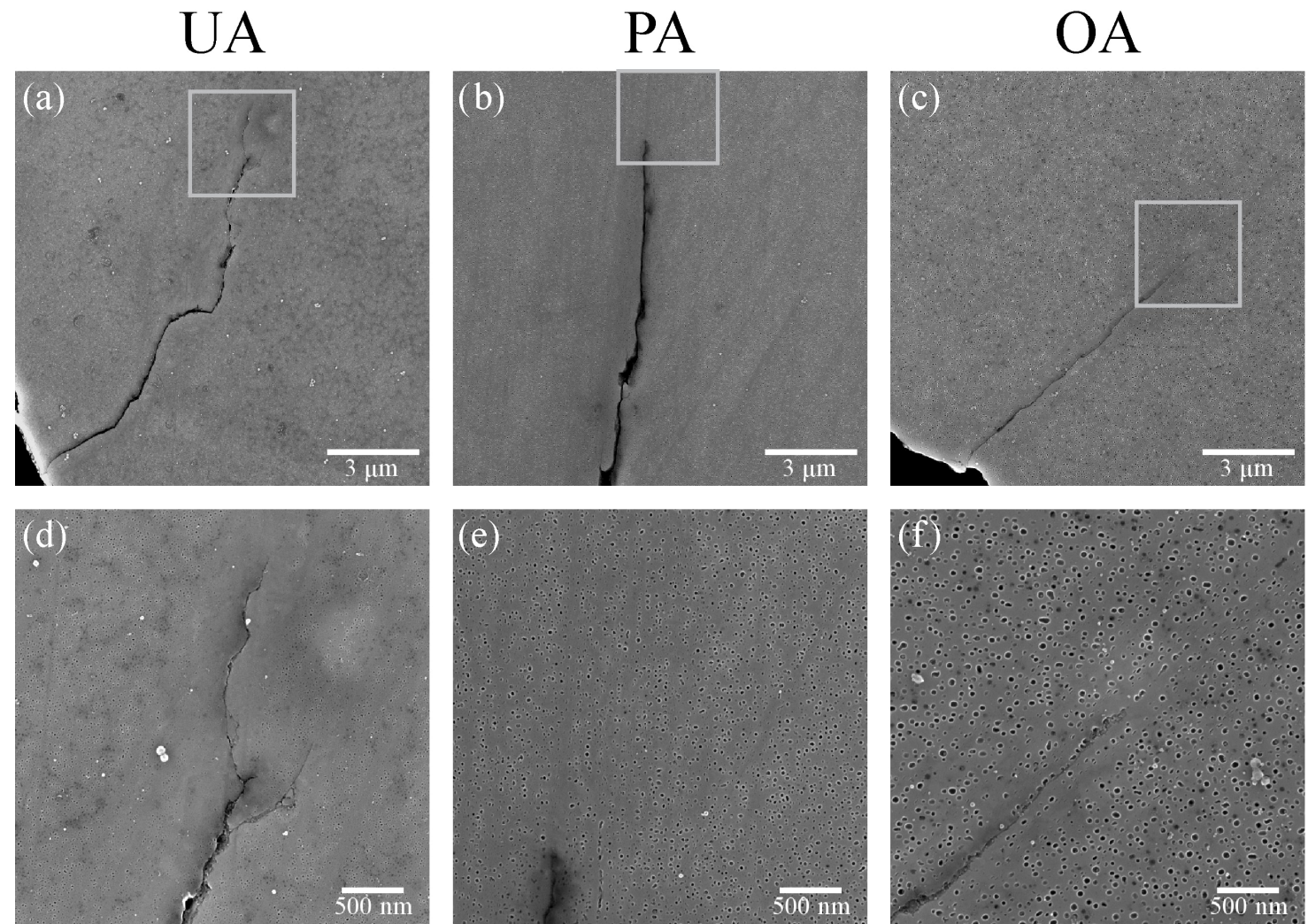

Figure 7: Secondary electron micrographs of surface cracks in the UA, PA and OA $\gamma^{\prime}$-etched samples. The enclosed regions in (a-c) are shown at a higher magnification in (d-f).

where $E$ is the Young's modulus, $M$ the Taylor factor, $b$ the Burgers vector, $\rho_{m}$ the mobile dislocation density and $v$ the average velocity of these dislocations. This ignores crystal orientation effects and averages the plastic deformation in multiple grains via the Taylor factor rather than considering the individual Schmid factors as done explicitly in crystal plasticity.

The contribution of the $\gamma^{\prime}$ phase to the yield stress is calculated as a function of the precipitate diameter $r$ and the antiphase boundary energy $\gamma_{A P B}$ from classical precipitation hardening theory (Reppich, 1982 , Ardell, 1985, Ardell and Huang, 1988). Two regimes, weak and strong pair-coupling, are modelled from the 
forces felt by two dislocations gliding on the same slip plane. The contribution to the critical resolved shear stress due to weakly paired dislocations $\tau_{w c}$ follows equation

$$
\tau_{w c}=\frac{d \gamma_{A P B}}{2 b^{2} L}\left(\frac{d \gamma_{A P B}}{\mu}\right)^{1 / 2}
$$

where $\mu$ is the shear modulus and $L$ the mean precipitate spacing. An additional term $-f$ typically appears inside the square root in equation (3), which arises from considering that the trailing dislocation has already entered a $\gamma^{\prime}$ at the critical point for precipitate shearing. This has been shown to introduce errors for alloys with small precipitates (Galindo-Nava, 2015) and is therefore avoided in the current derivation. For larger precipitates, strong pair-coupling is given by

$$
\tau_{s c}=\frac{W \mu b}{\pi L}\left(\frac{\pi d \gamma_{A P B}}{W \mu b^{2}}-1\right)^{1 / 2}
$$

where $W$ is a dimensionless constant used to account for uncertainties in the model and fit the results. The reader is referred elsewhere (Reed, 2006) for a more detailed derivation of these equations. The precipitate spacing

$$
L=\left(\frac{\pi}{6 f}\right)^{1 / 2} d
$$

can then be substituted into equations (3) and (4). The active mechanism will be that which requires the lowest stress to occur, i.e. $\sigma_{P}=M \min \left(\tau_{w c}, \tau_{s c}\right)$. Orowan bowing would be expected to occur for even larger precipitates, but this mechanism is ignored here as it is not expected to appear in the microstructures modelled in this work (due to their relatively small precipitates) and because loops seem to collapse anyway once dislocation multipoles and pile ups form within fully developed slip bands (León-Cázares et al., 2020).

Kinematic hardening is promoted both by the back stresses from dislocation pile ups and by the presence of a secondary phase due to the incompatibilities that arise upon deforming a material with elastic inclusions (Brown and Stobbs, 1971, Brown and Clarke, 1975). An empirical Armstrong-Frederick equation (Frederick and Armstrong, 2007; Halama et al., 2012) which has been proved effective in modelling precipitate-strengthened materials (Maciejewski and Ghonem, 2014, Zecevic and Knezevic, 2015) is cast in its differential form

$$
d \sigma_{K} / c_{2}=c_{1} d \epsilon_{p}-\sigma_{K}\left|d \epsilon_{p}\right|,
$$

where $c_{1}$ and $c_{2}$ are fitting constants. Upon disposing of the absolute value via the use of sign $\dot{\epsilon}$, integration of equation 6 leads to

$$
\sigma_{K}=c_{1} \operatorname{sign} \dot{\epsilon}+\left(\sigma_{K 0}-c_{1} \operatorname{sign} \dot{\epsilon}\right) \exp \left[-c_{2} \operatorname{sign} \dot{\epsilon}\left(\epsilon_{p}-\epsilon_{p 0}\right)\right],
$$

which is solved each time the load is reversed with $\sigma_{K 0}$ and $\epsilon_{p 0}$ the values of $\sigma_{K}$ and $\epsilon_{p}$ at that point (both set equal to zero at the beginning of the first cycle), respectively. The physical interpretations of $c_{1}$ and $c_{2}$ lie beyond the scope of the current study, and linking these to the precipitate evolution represents an additional challenge that must be tackled separately.

\subsection{Cyclic hardening}

The dislocation density acts as the main internal variable to determine the gradual hardening due to plastic straining. However, due to the slip localisation observed in this alloy, not all regions show an increase in the dislocation density. Thus, the evolution of the slip band volume fraction $f_{S B}$ is incorporated taking into account the behaviours observed with ECCI.

This composite material description makes it possible to split the total dislocation density $\rho$ into

$$
\rho=f_{S B} \rho_{S B}+\left(1-f_{S B}\right) \rho_{0},
$$

where the subindex $S B$ stands for a local variable at the slip bands and $\rho_{0}$ is the initial dislocation density, which remains unchanged in the interband regions. Equations (2) and (8), accounting only for mobile 
dislocations, lead to the decomposition of the plastic strain $\epsilon_{p}$ in a similar fashion. Even when dislocations in the interband region have an effect on the flow stress in planar slip materials, their density and mobility are much lower than those within the slip bands (Stoltz and Pineau, 1978; Ananthakrishna, 2007). Thus, the macroscopic plastic strain is dictated by the local strain at the slip bands

$$
\epsilon_{p}=f_{S B} \epsilon_{S B, p}
$$

The local plastic strain at the slip bands acts as a link between different mechanisms related to the evolution of the cyclic stress.

A Kocks-Mecking framework is incorporated by accounting for the composite model. From the chain rule this gets the form

$$
\frac{d \rho_{S B}}{d \epsilon_{p}}=\frac{\partial \rho_{S B}}{\partial \epsilon_{S B, p}} \frac{d \epsilon_{S B, p}}{d \epsilon_{p}}
$$

This equation links the local behaviour at the slip bands with the overall dislocation density responsible for the isotropic hardening. The first term in the right-hand side of equation $[10$ corresponds to the local evolution of the dislocations due to plastic strain, while the second term refers to the degree of localisation of slip.

The slip band behaviour can be modelled by a Kocks-Mecking equation (Kocks and Mecking, 2003) by accounting exclusively for the local plastic deformation

$$
\frac{d \rho_{S B}}{d \epsilon_{S B, p}}=k_{1} \sqrt{\rho_{S B}}-k_{2} \rho_{S B}
$$

where $k_{1}$ and $k_{2}$ are the dislocation storage and dynamic recovery coefficients. Combining equations (9), (10) and (11), the evolution of the dislocation density can be expressed as

$$
\frac{d \rho_{S B}}{d \epsilon_{p}}=\left(k_{1} \sqrt{\rho_{S B}}-k_{2} \rho_{S B}\right)\left(\frac{1}{f_{S B}}-\frac{\epsilon_{p}}{f_{S B}^{2}} \frac{d f_{S B}}{d \epsilon_{p}}\right) .
$$

The first parenthesis on the right-hand side of equation 12 determines the saturation of the isotropic hardening due to a gradual increase in the dislocation density. The second parenthesis links the localised deformation with the macroscopic strain via the volume fraction of slip bands; the first term converts the local variable to a global dislocation density in agreement with equation (8) and the second term acts as an additional source of dislocations due to the generation of new slip bands. The latter must have a larger effect during the first loading stage as the slip bands develop, and its effect becomes negligible once saturation of $f_{S B}$ is reached.

The evolution of $f_{S B}$ is modelled by accounting for the faster formation of slip bands within the initial cycles of the tests. This behaviour cannot be achieved solely from a dependence on $\epsilon_{p}$ due to the cyclic nature of the load. Instead, this is done with a variable

$$
q=\max \left(\left|\epsilon_{p}\right|, q\right)
$$

that records the maximum plastic strain that has been attained at any point during the fatigue test. This provides a physical meaning to the behaviour observed in other models, such as that of Maciejewski and Ghonem (Maciejewski and Ghonem, 2014), who have used a similar variable on an empirical model for isotropic hardening. The volume fraction of slip bands is then assumed to follow the empirical equation

$$
f_{S B}=f_{S B 0} \sqrt{q}
$$

where $f_{S B 0}$ can be fitted to the values measured experimentally. A similar dependence can be imposed on experimental data of slip band spacings reported in the literature (Lerch and Gerold, 1987). This phenomenological description reproduces the behaviour observed, but further modelling is required to explain the physical basis and dependences of $f_{S B 0}$. 
Equations (13) and (14) allow the formation of additional slip bands at later stages of cyclic tests with varying stress amplitudes. Prolonged softening may increase the amount of plastic deformation in every cycle, demanding the activation of new slip bands. Similarly, more slip bands form in grains closer to fatigue cracks (Clavel and Pineau, 1982) due to the higher local plastic strains attained in those areas.

The dislocation density at the slip bands can be extracted from the previous analysis by solving differential equation (12). Mughrabi's composite model for heterogeneous dislocation distributions (Mughrabi. 1987), originally developed for the cell structure deformation mechanism in wavy slip materials, is not employed here as it assumes that both regions are loaded in series. Instead, a standard Taylor equation

$$
\sigma_{D}=M \alpha_{S B} \mu b \sqrt{\rho}
$$

is used to estimate the work hardening contribution to the macroscopic flow stress, where the geometrical factor $\alpha$ accounts for the type and arrangement of dislocations (Mughrabi, 2016).

\subsection{Cyclic softening}

Precipitate shearing due to the accumulation of slip irreversibilities is considered here the only cause for cyclic softening. This loss in strength is modelled as an extension of classical precipitate hardening theory. The dislocation/particle interactions appear to be complex as not only the area of the cross section of a sheared precipitate decreases, but also its shape changes. In reality, this should have an effect on variables inherent to the calculation of precipitate strengthening, such as the bowing angle. For simplicity, a model is derived from the seminal ideas by Differt et. al. (Differt et al., 1987) (further detailed in Appendix A), with the additional assumptions:

- All the slip bands have the same morphology, consisting of $m_{s l}$ slip lines equally spaced by a distance $a$.

- The shearing process in each precipitate occurs in the direction of its nearest neighbour, situated at a distance $L_{e f f}=L$.

Upon shearing, the mean cross sectional sectional area of the precipitates $\overline{A_{A P B}}$ decreases, but the interparticle distance $L$ remains constant. A softening curve arises from substituting $d$ in equations (3) and 44 with an associated reduced precipitate diameter $\overline{d_{A P B}}=2 \sqrt{\overline{A_{A P B}} / \pi}$. This takes into account the physical evolution of the precipitate degradation phenomenon. A link between the reduction in $\overline{A_{A P B}}$ and the cumulative local plastic strain $\epsilon_{S B, p, c u m}$ is required to incorporate this dependence into the model.

The movement of dislocations inducing plastic strain occurs at individual slip planes. From Orowan's equation (equation (2), a description for an increment in the local cumulative plastic strain in a representative volume $V=w l \delta x$ can be given as

$$
\delta \epsilon_{S B, p, c u m}=M^{-1} b \delta x \rho_{S B, m},
$$

where $\delta x$ is the distance travelled by the dislocations and the subindex $m$ stands for mobile dislocations. Assuming that all the dislocations have the same length $l$, the mobile dislocation density can be expressed as

$$
\rho_{S B, m}=\frac{m_{s l} n_{p} l}{V},
$$

where $n_{p}$ is the average number of dislocations gliding per plane; thus, combining equations (16) and (17) and performing the integration gives

$$
n_{p}=\frac{a}{b} M \epsilon_{S B, p, c u m} .
$$

Introducing a factor $p$ that denotes the fraction of dislocations that undergo an irreversibility process after glide, the average number of irreversible steps per plane can be calculated as $n_{p, i r r}=p n_{p}$. This irreversibility factor may depend on the immobile dislocation density, which promotes both dislocation trapping and annihilation, but is assumed here to remain constant throughout the tests, for simplicity. 
Then, the expected number of irreversible steps in each direction per slip line $z$ at any point of a deformation process is

$$
z=\frac{a p}{2 b} M \epsilon_{S B, p, c u m}
$$

The methodology proposed by Differt et. al. (Differt et al., 1987) estimates the probability function of the number of irreversible slip steps in a single plane $\Delta n$. From this it is possible to calculate the probability function $P$ of shear step lengths $s=b \Delta n$, which takes the form

$$
P(s)=\exp (-2 z) I_{s / b}(2 z)
$$

where $I_{s / b}$ is the modified Bessel function of the first kind.

Let us now consider how each shear step modifies the cross sectional area $A_{A P B}$ of a precipitate along that slip plane. This is the area that the dislocations have to cross and it is delimited by the distance $L_{A P B}$, schematically shown in Figures 8 (a) and (b).

(a)

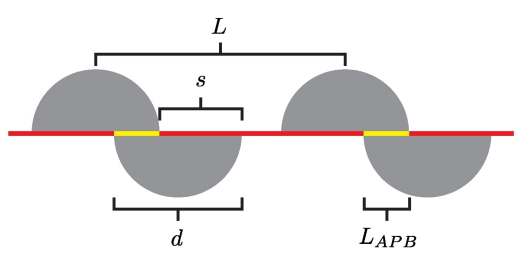

(c) $L>2 d$

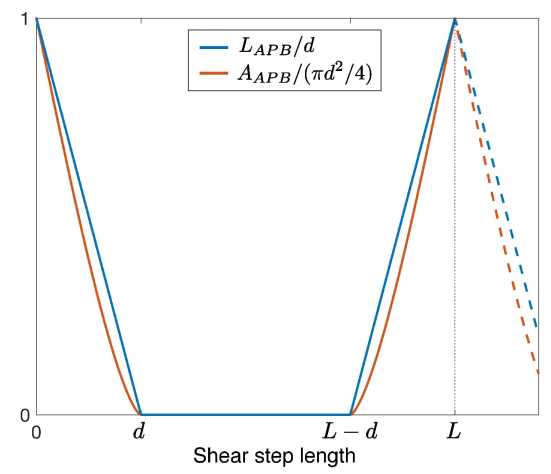

(b)

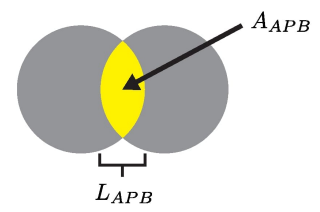

(d) $L \leq 2 d$

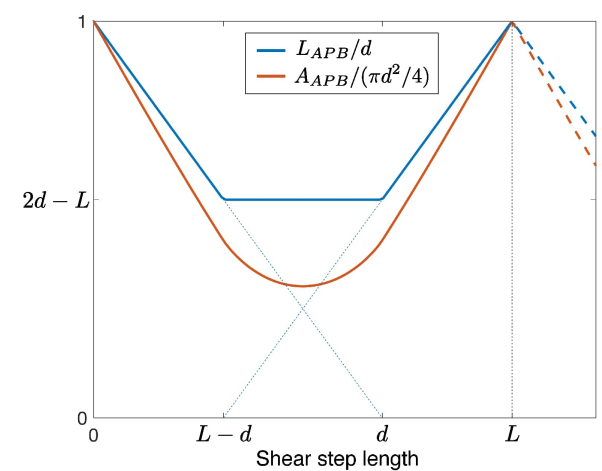

Figure 8: (a) Lateral view and (b) top view of the sheared precipitate configuration, and the normalised $L_{A P B}$ and $A_{A P B}$ as a function of the shear step length for microstructures with (c) $L>2 d$ and (d) $L<2 d$. The periodic boundaries at $s=L$ are represented by the dashed black lines.

For $L>2 d$, one can see that as $s$ increases, the distance $L_{A P B}$ decreases linearly from its initial value $L_{A P B}=d$ until it vanishes when $s=d$. However, once $s=L-d$ the bottom half makes contact with the top half of the precipitate next to it, restoring part of the previously lost antiphase boundary. This behaviour has been observed before (Sundararaman et al. 1990; León-Cázares et al., 2020). Once $s=L$, these fully overlap and $L_{A P B}$ takes its initial value. If $s$ keeps increasing after this the whole process repeats; thus, an effective slip step length can be defined from this symmetry as

$$
s_{\text {eff }}=\bmod (s, L) .
$$

The area where two equal circles shifted by distance $s$ intersect can be described by the relation

$$
A_{\text {int }}(s)=\frac{d^{2}}{2} \cos ^{-1}\left(\frac{s}{d}\right)-\frac{s}{2} \sqrt{d^{2}-s^{2}} .
$$


Thus, $A_{A P B}$ follows a similar trend to $L_{A P B}$, although it decreases from its initial value following equation (22) rather than linearly. Both curves, normalised to their initial values, are schematically shown in Figure $8(\mathrm{c})$.

These values behave differently when $L \leq 2 d$ (higher volume fractions) as the bottom half of a precipitate will start contacting the neighbouring particle before being totally separated from its original top half, which is represented in Figure 8(d). The plateau displayed in this curve originates from adding the two smaller $L_{A P B}$ segments formed at both ends of each particle. The resulting equations for these parameters as a function of the effective slip step length, for any $L / d$ ratio, can be expressed from geometric considerations as

$$
L_{A P B}\left(s_{e f f}\right)=\max \left(-s_{e f f}+d, s_{e f f}-L+d, 2 d-L, 0\right)
$$

and

$$
A_{A P B}\left(s_{e f f}\right)=A_{\text {int }}\left(s_{\text {eff }}\right)+A_{\text {int }}\left(L-s_{\text {eff }}\right) .
$$

Upon combining these geometric parameters with the probability function $P(s)$, the individual probabilities of each $|s|>L$ must be mapped into the domain of $s_{e f f}$ due to periodic symmetry. An associated $P\left(A_{A P B}\right)$ is immediately obtained from this, and as these are discrete distributions, the mean values $\overline{A_{A P B}}=A_{A P B} P\left(A_{A P B}\right)$ and $\overline{d_{A P B}}$ can be calculated. Substituting $d$ in equations (3) and (4) with $\overline{d_{A P B}}$, and combining it with equation $(19)$, leads to the evolution of $\sigma_{P}$ as a function of the local cumulative plastic strain. Note that the initial value of $L$ remains constant throughout a simulation. This results in a monotonically decreasing $\sigma_{P}$ function that still accounts for the competition between the weak and strong pair-coupling mechanisms but with the degraded geometry of the precipitates.

\subsection{Application of the model}

Implementation of the isotropic and kinematic hardening equations is done in an incremental way from the onset of plastic deformation for each tensile and compressive stage to capture the history dependent nature of plasticity. Differential equation 10 is solved with 0.002 plastic strain increments with the Matlab built-in function ode15s and the local cumulative plastic strain is used to update the value of $\sigma_{P}$ to account for the cyclic softening. The curve of $\sigma$ as a function of $\epsilon_{p}$ from the different strengthening contributions is then combined with the elastic component of the strain and forced to stop when it reaches the required amplitude, at which point the calculations for the next loading stage start.

Table 5 contains the values used for all input parameters of the model. Material parameters $\alpha, \rho_{0}$ and $b$ are selected from values typically reported in the literature. The value of $\alpha$ varies between 0.1 and 0.4 depending on many factors and may even evolve during a test, and a value of 0.2 appears often for heterogeneous dislocation patterns (Mughrabi, 1987, 2016). The initial dislocation density $\rho_{0}$ does not significantly affect the results, and the variation in Burgers vector between different superalloys is negligible, so these parameters were set from the beginning.

The Kocks-Mecking and kinematic hardening coefficients should vary for the different ageing conditions, but a single value is used for all tests. While this introduces errors in the simulations, this is preferred over overfitting. This also allows the variables characterised to show their effects on the evolution of the cyclic stress response, e.g. $d$ and $f_{S B 0}$. This last value is set for each sample so that the resulting $f_{S B}$ agrees with the experimental value for the corresponding plastic strain amplitude using equation (14). The initial value of $f_{S B}$ is artificially set to half of its value after the first strain increment to avoid dividing over zero in equation (10) while having a negligible contribution to the evolution of the dislocation density. Physically, this accounts for the dislocation sources that form the nuclei for the first slip bands developed.

As all the precipitate-reinforced samples were heat treated at the same temperature, the $\gamma^{\prime}$ volume fraction is expected to be equal. The small variation measured was thus neglected. The yield stresses were then calculated from the difference between the solutionised and the aged samples by choosing appropriate values of $\gamma_{A P B}$ and $W$. Note that precipitate hardening in these samples is considerably lower than that reported in this alloy at room temperature for the conventional $\delta / \eta$-subsolvus heat treatment (Kennedy, 2005, Cao and Kennedy, 2006, ATI Allvac, 2008) (1124 MPa (ATI Allvac, 2008)). The calculated initial precipitate strengthening contribution of alloy 718Plus as a function of precipitate size and its evolution in 
Table 5: Input parameters for the simulations.

\begin{tabular}{|c|c|c|}
\hline Parameter & 718Plus & Nimonic PE16 \\
\hline$M[-]$ & 3.06 & 3.06 (Taylor, 1938) \\
\hline$\alpha[-]$ & 0.2 & 0.2 (Mughrabi, 1987, 2016) \\
\hline$b[\mathrm{~nm}]$ & 248 & 248 (Galindo-Nava et al. 2015) \\
\hline$\mu[\mathrm{GPa}]$ & 82.7 & $66.4($ Pottebohm et al. 1983$)$ \\
\hline$E[\mathrm{GPa}]$ & 212.3 & 172.6 \\
\hline$\gamma_{A P B}\left[\mathrm{~J} / \mathrm{m}^{2}\right]$ & 0.16 & 0.15 \\
\hline$W[-]$ & 0.4 & 0.7 \\
\hline$\sigma_{0}[\mathrm{MPa}]$ & 110 & 270 \\
\hline$c_{1}[\mathrm{MPa}]$ & 340 & 250 \\
\hline$c_{2}[-]$ & 500 & 110 \\
\hline$k_{1}\left[\mu \mathrm{m}^{-1}\right]$ & 150 & 250 \\
\hline$k_{2}[-]$ & 5.6 & 7.9 \\
\hline$\rho_{0}[\mathrm{~m}-2]$ & $10^{10}$ & $10^{10}$ \\
\hline$d[\mathrm{~nm}] *$ & $0,14.1,27.5,38$ & $12.5,21,30$ \\
\hline$f[-]$ & 0.215 & 0.07 \\
\hline$f_{S B O}[-] *$ & $7.2,4,4.3,6.3$ & 4.3 \\
\hline$a[\mathrm{~nm}]$ & 21.7 & 21.7 \\
\hline$p[-]$ & 0.4 & 0.3 \\
\hline
\end{tabular}

terms of the local cumulative plastic strain are shown in Figure 9. As expected, larger precipitates take longer to lose their strength as more dislocations are required to shear them.

(a)

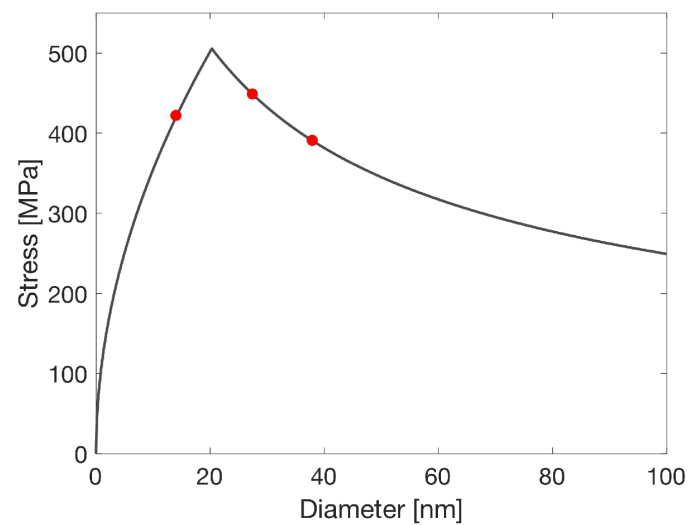

(b)

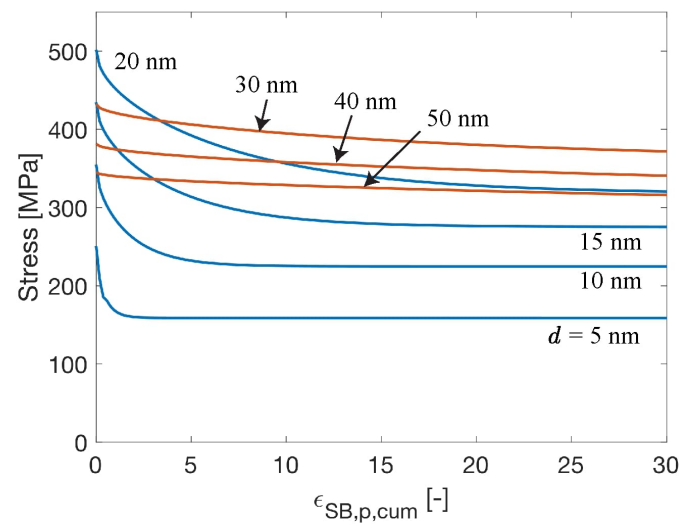

Figure 9: (a) Precipitate contribution to the yield stress as a function of diameter, where the red dots correspond to the UA, PA and OA samples in this study. (b) Evolution of this contribution as a function of the local cumulative plastic strain for different precipitate sizes. The blue and red lines correspond to underaged and overaged samples, respectively.

The kinematic hardening coefficients, the Kocks-Mecking parameters and the irreversibility factor $p$ were manually selected to fit all the curves produced. Figure 10 shows a comparison between the experimental and the simulated cyclic response in all samples. Trends in the cyclic plastic behaviour of the different ageing conditions are reproduced. As mentioned before, modelling of softening in the S sample is not done here due to the absence of precipitates.

The crossover between the curves of the PA and the OA samples is of particular interest. This is a consequence of two factors. Firstly, the lower softening rate in the latter due to precipitate size. Secondly, a 


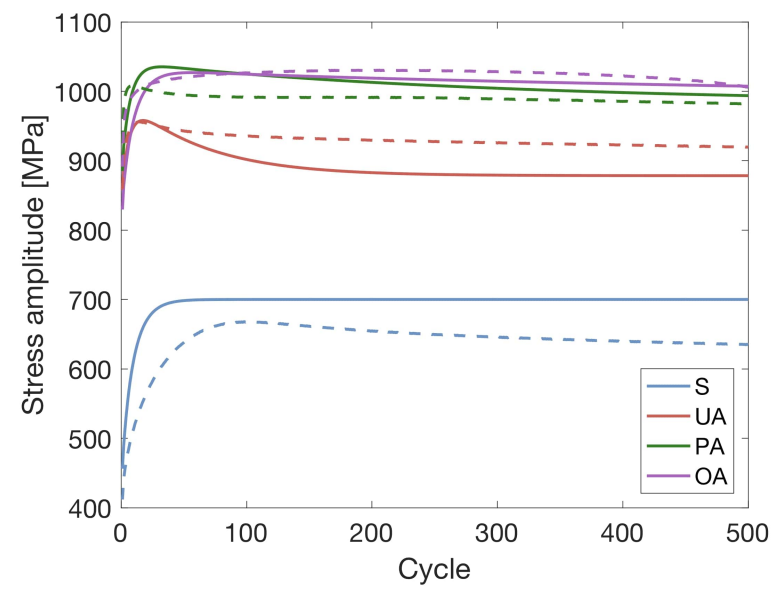

Figure 10: Experimental (dashed lines) and simulated (solid lines) evolution of the cyclic stress amplitude of the 718Plus samples.

higher volume fraction of slip bands in this condition. While $\rho_{S B}$ saturates at the same value for all samples, $\rho$ becomes larger for the OA condition, increasing the isotropic hardening. Another effect of the higher $f_{S B}$ is that each band must accommodate a lesser amount of plastic deformation per cycle, so that the cyclic hardening behaviour becomes slower. Thus, the maximum stress amplitude in the S and OA samples is reached after a higher number of cycles compared to the other materials.

Figure 11 shows the first and last cyclic stress-strain hysteresis curves for the precipitate-strengthened samples. A close agreement between experiments and simulations is observed. The largest difference appears in the OA sample, which hardens more slowly in the simulation; the larger $f_{S B}$ does not increase the hardening rate enough to match the experimental curve.

The model is also applied to experimental results from the literature in superalloy Nimonic PE16 fatigued at room temperature, with data from Sundararaman et al. (Sundararaman et al., 1989) and Singh et al. (Singh et al., 1991). These were selected because the tests performed vary both precipitate size and total strain amplitude, and characterisation of the precipitate size and volume fraction is also given. The input parameters of these simulations are shown in Table 5. A similar logic is followed to select the values used, with the exception of $f_{S B 0}$ and $a$, for which no data is available. For convenience, these are chosen to match the values in alloy 718 Plus.

Figure 12(a) shows the curves for the evolution of the stress amplitude in materials with different ageing times. Note that the horizontal scale is logarithmic as these tests ran until failure for close to 10000 cycles. These are also carried out at a lower strain amplitude of $0.57 \%$. The behaviours seen are similar to those described before; a crossover between the peak-aged and overaged conditions appears again and is also reproduced in the simulations. Unlike for 718 Plus, the same volume fraction of slip bands is used for all alloys, so this behaviour is purely due to the slower softening rate for larger precipitates.

LCF tests with different total strain amplitudes are shown in Figure 12(b) for the peak-aged condition, with simulation results that resemble the experimental curves. Another feature of the hardening model is showcased here. The macroscopic plastic strains these samples experience from the first cycle are different, those resulting in more slip bands being developed for higher amplitudes. Even though the local dislocation densities saturate at the same value for all tests, isotropic hardening does not. This agrees with classical work hardening theory, as a higher $f_{S B}$ implies that mobile dislocations will run into more forest dislocations. The trends followed by the maximum stress are fully reproduced, shifting towards larger stresses and lower number of cycles for higher strain amplitudes. This behaviour has been observed in other nickel-based superalloys (Stoltz and Pineau, 1978, Lerch and Gerold, 1987, Ganesh Sundara Raman and Padmanabhan, 1994). 

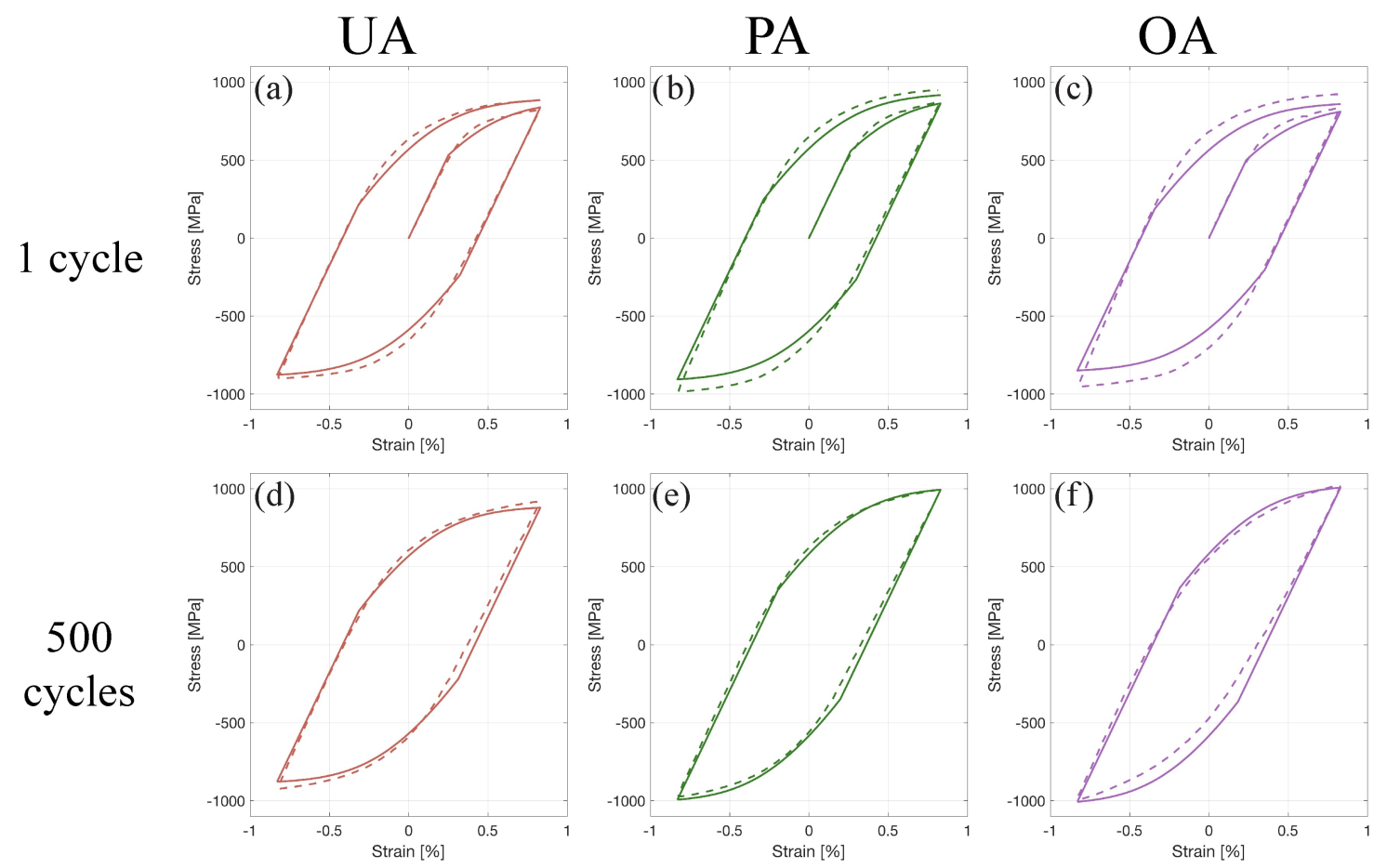

Figure 11: Experimental (dashed lines) and simulated (solid lines) stress-strain hysteresis curves of samples UA, PA and OA for cycles (a-c) 1 and (d-f) 500.

(a)

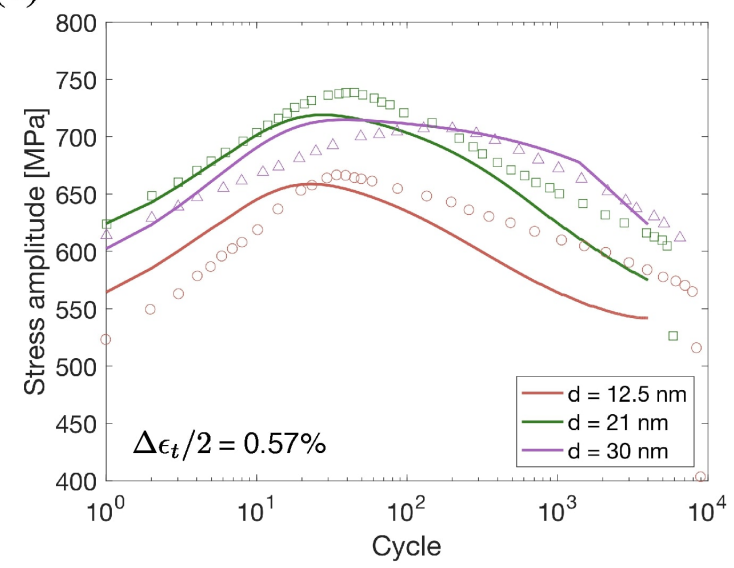

(b)

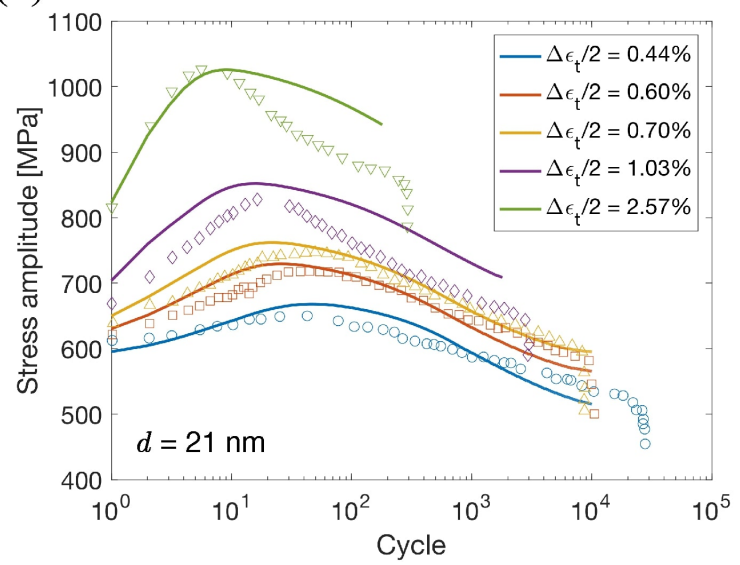

Figure 12: Experimental (markers) and simulated (solid lines) evolution of the cyclic stress amplitude of alloy Nimonic PE16 for (a) different precipitate sizes (Sundararaman et al. 1989) and (b) strain amplitudes (Singh et al. 1991).

\section{Discussion}

Slip bands are the main dislocation structure formed during LCF in superalloy 718Plus. The main difference in the deformation behaviour amongst all ageing conditions tested is the degree of slip localisation. Consider first the $\mathrm{S}$ condition. As mentioned before, a direct comparison with the other samples must be done with caution due to the difference in plastic strain, but similar trends are expected to appear regardless of this. With the activation of a source, dislocations will generate and glide freely until back stresses force them to double cross slip onto nearby slip planes. The absence of obstacles means that dislocations 
will redistribute freely across the material, resulting in more homogeneous structures. On the contrary, dislocations in precipitate-reinforced materials are more likely to glide on an already active plane as the precipitates become weaker with continuous shearing along these planes, rather than double cross slipping onto a pristine plane. While the effect of a single dislocation may be negligible, pile ups may contribute significantly to microstructure degradation even for low plastic strains in monotonic loading.

The slip line spacings measured are comparable in length to the $\gamma^{\prime}$ diameter, so that most of the precipitates are sheared only at one or two planes. When required, double cross slip events can preferentially redistribute the plastic deformation in the matrix. The weaker cross sections in underaged materials are easily sheared, promoting a high slip localisation, while for longer ageing times dislocations encounter harder barriers and are forced to spread more. This results in the activation of more slip bands across entire grains, as observed in the OA condition. These behaviours are accounted for in the model via the phenomenological relation for the evolution of $f_{S B}$. Figure 13 shows the evolution of this parameter for the various strain amplitudes of the Nimonic PE16 simulations. Most of the slip bands are shown to form during the first cycle, with higher volume fractions for larger deformations. Afterwards, more slip bands develop once enough softening results in larger attained plastic strains. This dependence would also be expected to show different degrees of slip localisation across different regions of the material if incorporated into crystal plasticity models.

(a)

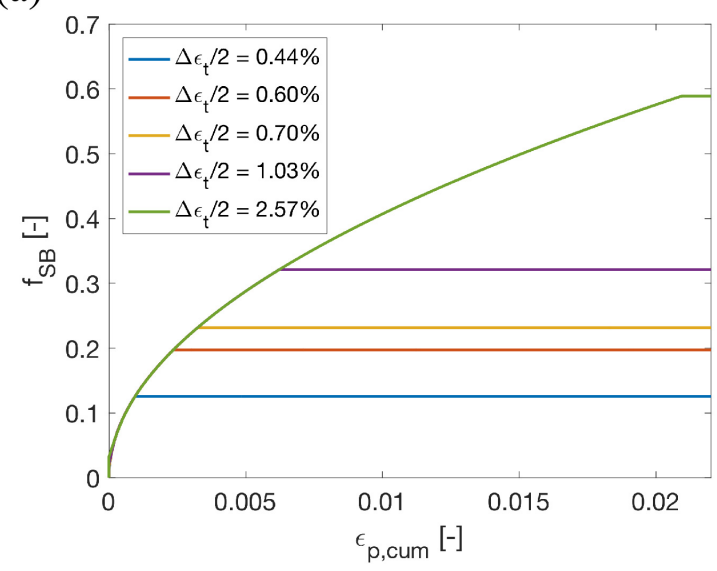

(b)

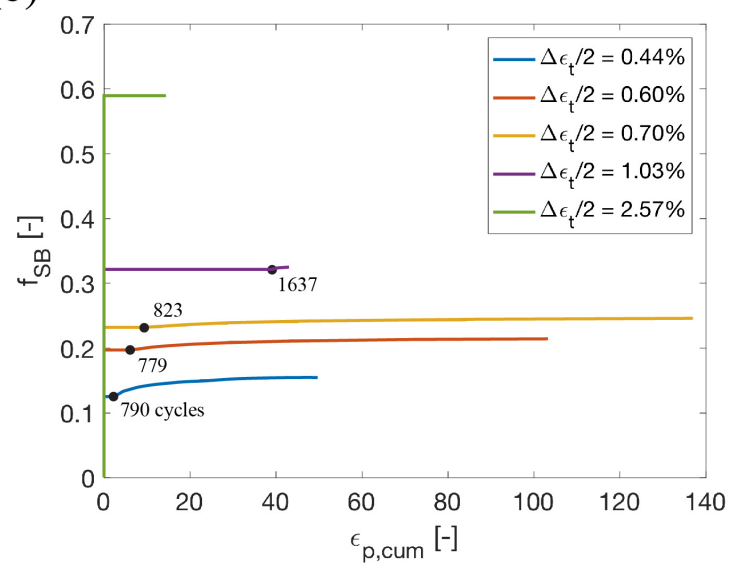

Figure 13: Evolution of the slip band volume fraction as a function of cumulative plastic strain for the different strain amplitudes in the Nimonic PE16 simulations from Figure 12 (b) for (a) the first cycle and (b) multiple cycles. The labelled dots indicate the number of cycles required to reach the cumulative plastic strains at which the slip band volume fraction starts increasing again.

The microstructure also evolves during cyclic loading. The continuous local degradation of the precipitates within the slip bands is captured by accounting for slip irreversibilities. This reflects the behaviours quantified in a previous study (León-Cázares et al., 2020), where the shear step lengths increase monotonically but more slowly with every cycle. These kinetics of degradation arise naturally in the model from considering the distribution of irreversibilities over multiple slip planes.

The model is able to reproduce trends of the macroscopic stress-strain response. Yet, its most important feature is accounting for the evolution of the dislocation structure and microstructure evolution. There is a physical meaning to every variable in the isotropic hardening and precipitate shearing models, which allows for a direct comparison between ageing conditions. Whilst there are evident differences between the experimental and the simulated curves, most of these could be reduced if the fitting parameters were changed for the different ageing conditions as done in most studies. Differences in the values of these parameters also have a physical origin, as the distinct microstructures would interact differently with the dislocations in general. However, doing this would risk not showing the actual effect of the variables related to the cyclic hardening and cyclic softening modelled here. 
The mesoscopic approach avoids dealing with phenomena at shorter length scales. For instance, the heterogeneity in precipitate size and distribution makes the cross sections to shear and the Friedel spacings variable, which affect the softening model. However, developing the equations as an extension from classical precipitate strengthening theory makes sure that these effects act equally on the initial yield stress and on the softening evolution due to shearing. Furthermore, the distances considered here all depend on the precipitate spacing $L$. The assumption that precipitate shearing occurs in the direction of the nearest neighbour implies that this analysis gives a lower bound for the plastic strain required for saturation of the precipitate hardening.

While there are a number of fitting parameters in the model, many of these are borrowed from existing models (e.g. $W, c_{1}, c_{2}, k_{1}, k_{2}$ ). Other physical descriptions have been developed for these phenomena elsewhere, but they include even more fitting parameters. Not being the primary scope of the current work, these are not further detailed. Alternatively, the slip localisation and precipitate shearing parts of the model rely only on one $\left(f_{S B 0}\right)$ and two $(a$ and $p)$ fitting parameters, respectively, all of which detailed more in depth.

A discussion is needed regarding the effect of precipitate shearing on the cyclic softening behaviour. While this is held in this model as the only mechanism responsible, it is evident that other phenomena have an influence too. This is clear from the results of the S sample and others from the literature (Valsan et al. 1994; Subramanya Sarma et al., 1998; He et al., 2002; Chai et al., 2004). The most reasonable explanation is the evolution of the dislocation structure (Pham et al., 2011, 2013). Slip bands develop during the initial cycles but a subsequent relaxation process towards more stable dislocation configurations may take more time.

The saturation of the cyclic softening process is modelled here based on the recombination of sheared precipitates. Due to the periodicity of the shearing process, there is always a remaining antiphase boundary contribution $\overline{A_{A P B, s a t}}($ Mughrabi, 1983, Sundararaman et al. 1990). This saturation limit of the softening process can be expressed as

$$
\overline{A_{A P B}, \text { sat }}=\lim _{z \rightarrow \infty} \sum_{A_{A P B}=0}^{\pi d^{2} / 4} A_{A P B} P\left(A_{A P B}\right)=\frac{1}{L} \int_{0}^{L} A_{A P B} d x=\frac{2}{3} \frac{d^{3}}{L}
$$

which in terms of the $\gamma^{\prime}$ volume fraction becomes

$$
\overline{A_{A P B, s a t}}=\left(\frac{2 f}{3 \pi}\right)^{1 / 2} d^{2}
$$

These results arise from a geometric analysis by considering the periodicity of the $A_{A P B}$ function. If the assumption that a precipitate half will travel in the direction of its nearest neighbour is false, i.e. $L_{e f f}>L$, then the initial softening rate will remain the same but the saturation stress will decrease. It suffices to substitute $L$ with a corresponding mean distance $L_{\text {eff }}$ in equations (21) and (25) to produce this change.

This saturation variable $\overline{A_{A P B, s a t}}$ may also have a connection with the precipitate dissolution observed in the UA sample near a crack. If precipitates within a slip band are sheared excessively so that the remaining particles are very small, nucleation theory dictates that dissolution may become energetically favourable. A balance between their area and volume would determine the condition for this process to begin. A similar plastic strain induced phase transition was observed and modelled by Brechet et al. in a Al-Li alloy. The energetics for dissolution due to chemistry are left beyond the scope of the current study, but equation (26) constitutes a prediction of its parametric dependence on microstructure. Smaller values of $\overline{A_{A P B, s a t}}$ are related to larger precipitate surface areas, which come with a higher chance of dissolution. The formation of precipitate-free deformation bands is predicted to be considerably more dependent on $\gamma^{\prime}$ size than volume fraction, explaining their appearance only for the UA condition. This is clearly observed in Figure 7(d). Additional dislocation behaviours that may promote precipitate dissolution are a reduction of slip line spacing and $\gamma^{\prime}$ shearing on multiple non-parallel slip planes.

The mesoscopic model is used here to predict the behaviour of a polycrystal, but similar ideas can be adapted at other length scales. Crystal plasticity could offer a more complete description of the distribution 
of slip bands within individual grains accounting for crystal orientation effects. A more accurate description for the softening behaviour can also be added to dislocation dynamics frameworks to further investigate the process of slip localisation during LCF.

Of particular importance is the incorporation of the ideas on the evolution of the microstructure to the description of fatigue damage. An empirical parameter for the prediction of crack initiation is the cumulative plastic strain (Manonukul and Dunne, 2004, Dunne et al., 2007; McDowell and Dunne, 2010), which is also related to precipitate shearing. While this might not be directly responsible for crack nucleation, the process can be thought of as a feedback loop. Slip localisation produces local softening, which further promotes slip along the sheared planes. This is also associated with the formation of extrusion and intrusions that precede crack nucleation (Essmann et al., 1981; Risbet et al., 2003; Déprés et al., 2004; Risbet et al., 2009). The high stresses ahead of the crack tip induce high plastic strains that locally soften the material even more and promote more slip localisation. In this way, damage accumulation takes place over multiple cycles along severely damaged slip bands.

\section{Conclusions}

This study offers new insights into the phenomena of slip localisation and precipitate degradation in nickel-based superalloys during LCF. Different ageing conditions of alloy 718Plus are investigated by means of ECCI for the dislocation structure and through-lens detector in $\gamma^{\prime}$-etched samples for the precipitate shear behaviour, with emphasis on the effects of precipitate size. The presence of shearable precipitates is shown to increase the degree of localisation of plastic deformation, but slip bands spread more homogeneously across the grains for larger particles. This, together with the higher number of dislocations required to shear a precipitate, are deemed responsible for the slower softening rates observed in overaged samples.

An original mesoscopic model developed based on these phenomena is able to reproduce trends observed in 718Plus and Nimonic PE16. The main features of the model are:

- A composite model for isotropic hardening based on slip localisation within slip bands. A phenomenological description for the formation of slip bands is able to reproduce the plastic strain heterogenisation at the grain length scale and the stress saturation variation as a function of strain amplitude at the macroscopic level.

- A physics-based description of the cyclic softening behaviour based on the mechanism of continuous $\gamma^{\prime}$ shearing. The model extends classical precipitation hardening through a geometric analysis on the sheared cross sections to account for the gradual loss in strength.

- A link between both modelling ideas by means of an explicit slip band volume fraction.

The ideas explored have deep implications both in the evolution of cyclic deformation and in the crack initiation process. Microscopy performed close to surface cracks shows higher degrees of plastic strains, with the formation of precipitate-free deformation bands in the underaged condition, which is explained by dissolution linked to the saturation limit of $\gamma^{\prime}$ shearing.

\section{Acknowledgements}

F.D. León-Cázares is grateful for funding from CONACyT, the Cambridge Trust and the Roberto Rocca Education Program. E.I. Galindo-Nava acknowledges funding from RAEng for his research fellowship. We also acknowledge Rolls-Royce plc and the Engineering and Physical Sciences Research Council (EPSRC) for financial support under the Strategic Partnership, Grant Numbers EP/ H022309/1 and EP/H500375/1, and thank Rolls-Royce Deutschland for supplying the material. 


\section{Appendix A. Distribution of slip irreversibilities}

Differt et al. (Differt et al., 1987) proposed a model for the precipitate shearing phenomenon that accounts for the dislocation irreversibilities in a probabilistic way by considering the following assumptions:

(i) The probability $P$ that there are $n^{+}$positive slip steps in a glide plane is given by a Poisson distribution

$$
P\left(n^{+}\right)=\frac{z^{n^{+}}}{n^{+!}} \exp (-z)
$$

where $z=Z a / 2 t$ and $Z$ is the total number of slip steps in a region with thickness $t$.

(ii) There is an equal distribution of positive and negative slip steps $n^{-}$, thus $P\left(n^{+}\right)=P\left(n^{-}\right)$.

(iii) The same number of dislocations travel the same distance along the multiple slip lines.

(iv) The probability of getting a new positive (or negative) slip step is history-independent.

Then, to calculate the probability of finding a number $\Delta n=n^{+}-n^{-}$of slip steps in a slip plane, a sum over the products of the probabilities $P\left(n^{+}\right) P\left(n^{-}\right)$is done; i.e.

$$
P(\Delta n)=\sum_{n^{-}=0}^{Z / 2} P\left(\Delta n+n^{-}\right) P\left(n^{-}\right),
$$

and substituting equation A.1 into A.2.

$$
P(\Delta n)=\sum_{n^{-}=0}^{Z / 2} \frac{z^{\Delta n+2 n^{-}}}{\left(\Delta n+n^{-}\right) ! n !} \exp (-2 z) .
$$

Considering the infinite summation of the $n^{-}$values, equation A.3 takes the form of the modified Bessel function of the first kind $I_{\alpha}$, so that

$$
P(\Delta n)=\exp (-2 z) I_{\Delta n}(2 z)
$$

This is a reasonable assumption given that $Z$ takes very large numbers.

\section{References}

Ananthakrishna, G., 2007. Current theoretical approaches to collective behavior of dislocations. Phys. Rep. 440, $113-259$. https://doi.org/10.1016/j.physrep.2006.10.003

Antolovich, S.D., 2015. Microstructural aspects of fatigue in Ni-base superalloys. Philos. Trans. R. Soc., A 373, 2014012820140128. https://doi.org/10.1098/rsta.2014.0128

Antolovich, S.D., Rosa, E., Pineau, A., 1981. Low cycle fatigue of René 77 at elevated temperatures. Mater. Sci. Eng. 47, 47-57. https://doi.org/10.1016/0025-5416(81)90040-9

Ardell, A.J., 1985. Precipitation hardening. Metall. Trans. A 16, 2131-2165. https://doi.org/10.1007/BF02670416

Ardell, A.J., Huang, J.C., 1988. Antiphase boundary energies and the transition from shearing to looping in alloys strengthened by ordered precipitates. Philos. Mag. Lett. 58, 189-197. https://doi.org/10.1080/09500838808214752

ATI Allvac, 2008. 718 Plus(B) data sourcebook. Technical Report. ATI Allvac.

Banerjee, A., Sahu, J.K., Paulose, N., Fernando, C.D., Ghosh, R.N., 2016. Micromechanism of cyclic plastic deformation of alloy IN 718 at 600 C. Fatigue Fract. Eng. Mater. Struct. 39, 877-885. https://doi.org/10.1111/ffe.12406

Barrett, P.R., Ahmed, R., Menon, M., Hassan, T., 2016. Isothermal low-cycle fatigue and fatigue-creep of Haynes 230 . Int. J. Solids Struct. 88-89, 146-164. https://doi.org/10.1016/j.ijsolstr.2016.03.011

Basinski, Z., Basinski, S., 1992. Fundamental aspects of low amplitude cyclic deformation in face-centred cubic crystals. Prog. Mater. Sci. 36, 89-148. https://doi.org/10.1016/0079-6425(92)90006-S

Brechet, Y., Louchet, F., Marchionni, C., Verger-Gaugry, J.L., 1987. Experimental (TEM and STEM) investigation and theoretical approach to the fatigue-induced dissolution of $\delta$ ' precipitates in a 2.5 wt\% Al-Li alloy. Philos. Mag. A 56, 353-366. https://doi.org/10.1080/01418618708214391

Brown, L., Clarke, D., 1975. Work hardening due to internal stresses in composite materials. Acta Metall. 23, 821-830. https://doi.org/10.1016/0001-6160(75)90198-4

Brown, L.M., Stobbs, W.M., 1971. The work-hardening of copper-silica I. A Model based on Internal Stresses, with no Plastic Relaxation. Philos. Mag. 23, 1185-1199. https://doi.org/10.1080/14786437108217405

Calabrese, C., Laird, C., 1974. Cyclic stressstrain response of two-phase alloys Part I. Microstructures containing particles penetrable by dislocations. Mater. Sci. Eng. 13, 141-157. https://doi.org/10.1016/0025-5416(74)90182-7 
Cao, W.D., Kennedy, R., 2006. Recommendations for Heat Treating Allvac® 718Plusß Alloy Parts. Technical Report. ATI Allvac.

Casanova, A., Hardy, M., Rae, C., 2014. Morphology and Kinetics of Grain Boundary Precipitation in Alloy ATI 718Plusß, in: Int. Symp. Superalloy 718 Deriv., 8th. John Wiley \& Sons, Inc., Hoboken, NJ, USA, pp. 573-586. https://doi.org/10. 1002/9781119016854.ch45

Chai, G., Liu, P., Frodigh, J., 2004. Cyclic deformation behaviour of a nickel base alloy at elevated temperature. J. Mater. Sci. 39, 2689-2697. https://doi.org/10.1023/B: JMSC.0000021443.09342.3c

Choe, B.H., Lee, H.C., 1995. Cyclic softening and hardening behavior of a nickel-base superalloy. Scr. Metall. Mater. 32, 1283-1287. https://doi.org/10.1016/0956-716X(94)00018-D.

Clavel, M., Pineau, A., 1982. Fatigue behaviour of two nickel-base alloys I: Experimental results on low cycle fatigue, fatigue crack propagation and substructures. Mater. Sci. Eng. 55, 157-171. https://doi.org/10.1016/0025-5416(82)90129-X

Collins, D.M., Stone, H.J., 2014. A modelling approach to yield strength optimisation in a nickel-base superalloy. Int. J. Plast. 54, 96-112. https://doi.org/10.1016/j.ijplas.2013.08.009

Déprés, C., Robertson, C., Fivel, M., 2004. Crack initiation in fatigue: experiments and three-dimensional dislocation simulations. Mater. Sci. Eng. A 387-389, 288-291. https://doi.org/10.1016/j.msea.2003.12.084.

Differt, K., Essmann, U., Mughrabi, H., 1987. Models of particle destruction in fatigued precipitation-hardened alloys. Phys. Status Solidi (a) 104, 95-106. https://doi.org/10.1002/pssa.2211040107

Dunne, F., Rugg, D., Walker, A., 2007. Lengthscale-dependent, elastically anisotropic, physically-based hcp crystal plasticity: Application to cold-dwell fatigue in Ti alloys. Int. J. Plast. 23, 1061-1083. https://doi.org/10.1016/j.ijplas.2006.10.013

Essmann, U., Gösele, U., Mughrabi, H., 1981. A model of extrusions and intrusions in fatigued metals I. Point-defect production and the growth of extrusions. Philos. Mag. A 44, 405-426. https://doi.org/10.1080/01418618108239541

Frederick, C., Armstrong, P., 2007. A mathematical representation of the multiaxial Bauschinger effect. Mater. High Temp. 24, 1-26. https://doi.org/10.3184/096034007X207589

Fribourg, G., Bréchet, Y., Deschamps, A., Simar, A., 2011. Microstructure-based modelling of isotropic and kinematic strain hardening in a precipitation-hardened aluminium alloy. Acta Mater. 59, 3621-3635. https://doi.org/10.1016/j.actamat. 2011.02 .035

Galindo-Nava, E., Connor, L., Rae, C., 2015. On the prediction of the yield stress of unimodal and multimodal $\gamma^{\prime}$ Nickel-base superalloys. Acta Mater. 98, 377-390. https://doi.org/10.1016/j.actamat.2015.07.048

Galindo-Nava, E.I., 2015. Modelling twinning evolution during plastic deformation in hexagonal close-packed metals. Mater. Des. 83, 327-343. https://doi.org/10.1016/j.matdes.2015.06.025

Ganesh Sundara Raman, S., Padmanabhan, K., 1994. Room-temperature low-cycle fatigue behaviour of a Ni-base superalloy. Int. J. Fatigue 16, 209-215. https://doi.org/10.1016/0142-1123(94)90005-1

Gopinath, K., Gogia, A., Kamat, S., Balamuralikrishnan, R., Ramamurty, U., 2009. Low cycle fatigue behaviour of a low interstitial Ni-base superalloy. Acta Mater. 57, 3450-3459. https://doi.org/10.1016/j.actamat.2009.03.046

Halama, R., Sedlk, J., Ofer, M., 2012. Phenomenological Modelling of Cyclic Plasticity, in: Miidla, P. (Ed.), Numerical Modelling. InTech, Rijeka. chapter 15, pp. 329-354. https://doi.org/10.5772/35902.

Han, W., Vinogradov, A., Hutchinson, C., 2011. On the reversibility of dislocation slip during cyclic deformation of Al alloys containing shear-resistant particles. Acta Mater. 59, 3720-3736. https://doi.org/10.1016/j.actamat.2011.03.007

He, Y.H., Chen, L.J., Liaw, P.K., McDaniels, R.L., Brooks, C.R., Seeley, R.R., Klarstrom, D.L., 2002. Low-Cycle Fatigue Behavior of HAYNES HR-120 alloy. Int. J. Fatigue 24, 161-931-942. https://doi.org/10.1115/GT2007-28267

Henkel, S., Fischer, J., Balogh, L., Ungar, T., Biermann, H., 2010. Low-cycle fatigue behaviour and microstructure of copper and alpha-brass under biaxial load paths. J. Phys.: Conf. Ser. 240, 012042. https://doi.org/10.1088/1742-6596/240/1/012042

Ho, H., Risbet, M., Feaugas, X., 2015. On the unified view of the contribution of plastic strain to cyclic crack initiation: Impact of the progressive transformation of shear bands to persistent slip bands. Acta Mater. 85, 155-167. https://doi.org/10. 1016/j.actamat.2014.11.020

Huang, M., Zhao, L., Tong, J., 2012. Discrete dislocation dynamics modelling of mechanical deformation of nickel-based single crystal superalloys. Int. J. Plast. 28, 141-158. https://doi.org/10.1016/j.ijplas.2011.07.003

Humphreys, F., Hatherly, M., 2004. Recrystallization and related annealing phenomena. 2 ed., Elsevier, Oxford.

Kassner, M., Geantil, P., Levine, L., Larson, B., 2008. Backstress, the Bauschinger Effect and Cyclic Deformation. Mater. Sci. Forum 604-605, 39-51. https://doi.org/10.4028/www.scientific.net/MSF.604-605.39

Kennedy, R.L., 2005. ALLVAC® 718PLUS, superalloy for the next forty years. Superalloys 718, 625, 706 Deriv., Proc. Int. Symp., 6th 718, 625-706.

Kocks, U., Mecking, H., 2003. Physics and phenomenology of strain hardening: the FCC case. Prog. Mater. Sci. 48, 171-273. https://doi.org/10.1016/S0079-6425(02)00003-8.

Köhler, E., Bischoff, E., Gerold, V., 1984. Chemical analysis of persistent slip bands in an age-hardened aluminum-silver alloy by means of eds. Scr. Metall. 18, 699-702. https://doi.org/10.1016/0036-9748(84)90323-5

Krishna, E.H., Prasad, K., Kumar, V., Singh, V., 2010. Low cycle fatigue behaviour of modified and conventional superalloy Inconel 718 at 650C. Trans. Indian Inst. Met. 63, 63-66. https://doi.org/10.1007/s12666-010-0009-x

Landini, G., Randell, D., Fouad, S., Galton, A., 2017. Automatic thresholding from the gradients of region boundaries. J. Microsc. 265, 185-195. https://doi.org/10.1111/jmi.12474

Lee, J.K., Bhat, S.P., Veaux, R., Laird, C., 1981. Mechanisms of cyclic softening in precipitation-hardening alloys - A ball model approach and tests at 78 K. Int. J. Fract. 17, 121-141. https://doi.org/10.1007/BF00053516

León-Cázares, F., Schlütter, R., Jackson, T., Galindo-Nava, E., Rae, C., 2020. A multiscale study on the morphology and evolution of slip bands in a nickel-based superalloy during low cycle fatigue. Acta Mater. 182, 47-59. https://doi.org/10. 1016/j.actamat.2019.10.033 
Lerch, B.A., Gerold, V., 1987. Cyclic hardening mechanisms in NIMONIC 80A. Metall. Trans. A 18 , $2135-2141$. https://doi.org/10.1007/BF02647085

Lerch, B.A., Jayaraman, N., Antolovich, S.D., 1984. A study of fatigue damage mechanisms in Waspaloy from 25 to 800 C. Mater. Sci. Eng. 66, 151-166. https://doi.org/10.1016/0025-5416(84)90177-0.

Li, Y., Laird, C., 1994. Cyclic response and dislocation structures of AISI 316L stainless steel. Part 2: polycrystals fatigued at intermediate strain amplitude. Mater. Sci. Eng. A 186, 87-103. https://doi.org/10.1016/0921-5093(94)90307-7

Lukáš, P., Kunz, L., 2004. Role of persistent slip bands in fatigue. Philos. Mag. 84, 317-330. https://doi.org/10.1080/ 14786430310001610339

Maciejewski, K., Ghonem, H., 2014. Isotropic and kinematic hardening as functions of gamma prime precipitates in a nickelbased superalloy. Int. J. Fatigue 68, 123-135. https://doi.org/10.1016/j.ijfatigue.2014.05.011.

Manonukul, A., Dunne, F.P.E., 2004. High and lowcycle fatigue crack initiation using polycrystal plasticity. Proc. R. Soc. London, Ser. A 460, 1881-1903. https://doi.org/10.1098/rspa.2003.1258

McDowell, D., Dunne, F., 2010. Microstructure-sensitive computational modeling of fatigue crack formation. Int. J. Fatigue 32, 1521-1542. https://doi.org/10.1016/j.ijfatigue.2010.01.003

Mello, A.W., Nicolas, A., Sangid, M.D., 2017. Fatigue strain mapping via digital image correlation for Ni-based superalloys: The role of thermal activation on cube slip. Mater. Sci. Eng. A 695, 332-341. https://doi.org/10.1016/j.msea.2017.04.002

Miner, R.V., Castelli, M.G., 1992. Hardening mechanisms in a dynamic strain aging alloy, HASTELLOY X, during isothermal and thermomechanical cyclic deformation. Metall. Trans. A 23, 551-561. https://doi.org/10.1007/BF02801173

Mughrabi, H., 1983. Cyclic deformation and fatigue of multi-phase materials, in: Deform. Multi-Phase Part. Containing Mater., Proc. Riso Int. Symp. Metall. Mater. Sci., 4th, Ris $\varnothing$ National Laboratory, Roskilde. pp. 65-82.

Mughrabi, H., 1987. A two-parameter description of heterogeneous dislocation distributions in deformed metal crystals. Mater. Sci. Eng. 85, 15-31. https://doi.org/10.1016/0025-5416(87)90463-0.

Mughrabi, H., 2009. Cyclic Slip Irreversibilities and the Evolution of Fatigue Damage. Metall. Mater. Trans. B 40 , $431-453$. https://doi.org/10.1007/s11663-009-9240-4

Mughrabi, H., 2013a. Cyclic slip irreversibility and fatigue life: A microstructure-based analysis. Acta Mater. 61, $1197-1203$. https://doi.org/10.1016/j.actamat.2012.10.029

Mughrabi, H., 2013b. Microstructural fatigue mechanisms: Cyclic slip irreversibility, crack initiation, non-linear elastic damage analysis. Int. J. Fatigue 57, 2-8. https://doi.org/10.1016/j.ijfatigue.2012.06.007

Mughrabi, H., 2016. The $\alpha$-factor in the Taylor flow-stress law in monotonic, cyclic and quasi-stationary deformations: Dependence on slip mode, dislocation arrangement and density. Curr. Opin. Solid State Mater. Sci. 20, 411-420. https://doi.org/10.1016/j.cossms.2016.07.001.

Nip, K., Gardner, L., Davies, C., Elghazouli, A., 2010. Extremely low cycle fatigue tests on structural carbon steel and stainless steel. J. Constr. Steel Res. 66, 96-110. https://doi.org/10.1016/j.jcsr.2009.08.004

Obrtlík, K., Petrenec, M., Man, J., Polák, J., Hrbáček, K., 2009. Isothermal fatigue behavior of cast superalloy Inconel 792-5A at 23 and 900 C. J. Mater. Sci. 44, 3305-3314. https://doi.org/10.1007/s10853-009-3446-3

Orowan, E., 1940. Problems of plastic gliding. Proc. Phys. Soc. 52, 8-22. https://doi.org/10.1088/0959-5309/52/1/303

Petrenec, M., Polák, J., Samoril, T., Dluhos, J., Obrtlík, K., 2014. In-Situ High Temperature Low Cycle Fatigue Study of Surface Topography Evolution in Nickel Superalloys, in: METAL 2014 Int. Conf. Metal. Mater.,23rd, Brno. pp. 1139-1144.

Pham, M., Holdsworth, S., Janssens, K., Mazza, E., 2013. Cyclic deformation response of AISI 316L at room temperature: Mechanical behaviour, microstructural evolution, physically-based evolutionary constitutive modelling. Int. J. Plast. 47, 143-164. https://doi.org/10.1016/j.ijplas.2013.01.017

Pham, M., Solenthaler, C., Janssens, K., Holdsworth, S., 2011. Dislocation structure evolution and its effects on cyclic deformation response of AISI 316L stainless steel. Mater. Sci. Eng. A 528, 3261-3269. https://doi.org/10.1016/j.msea. 2011.01 .015

Phillips, P., Unocic, R., Mills, M., 2013. Low cycle fatigue of a polycrystalline Ni-based superalloy: Deformation substructure analysis. Int. J. Fatigue 57, 50-57. https://doi.org/10.1016/j.ijfatigue.2012.11.008

Pickering, E., Mathur, H., Bhowmik, A., Messé, O., Barnard, J., Hardy, M., Krakow, R., Loehnert, K., Stone, H., Rae, C., 2012. Grain-boundary precipitation in Allvac 718Plus. Acta Mater. 60, 2757-2769. https://doi.org/10.1016/j.actamat. 2012.01 .042

Pineau, A., Antolovich, S.D., 2009. High temperature fatigue of nickel-base superalloys - A review with special emphasis on deformation modes and oxidation. Eng. Failure Anal. 16, 2668-2697. https://doi.org/10.1016/j.engfailanal.2009.01.010

Pottebohm, H., Neite, G., Nembach, E., 1983. Elastic Properties (the Stiffness Constants, the Shear Modulus and the Dislocation Line Energy and Tension) of Ni-AI Solid Solutions and of the Nimonic Alloy PE 16. Mater. Sci. Eng. 60, $189-194$.

Preuss, M., Withers, P.J., Pang, J.W.L., Baxter, G.J., 2002. Inertia welding nickel-based superalloy: Part I. Metallurgical characterization. Metall. Mater. Trans. A 33, 3215-3225. https://doi.org/10.1007/s11661-002-0307-y

Qin, H.y., Chen, G., Zhu, Q., Wang, C.j., Zhang, P., 2015. High temperature low cycle fatigue behavior of GH4742 alloy. J. Iron Steel Res. Int. 22, 551-556. https://doi.org/10.1016/S1006-706X(15)30039-X.

Reed, R.C., 2006. The Superalloys: Fundamentals and Applications. Cambridge University Press, Cambridge.

Reppich, B., 1982. Some new aspects concerning particle hardening mechanisms in $\gamma^{\prime}$ precipitating Ni-base alloysI. Theoretical concept. Acta Metall. 30, 87-94. https://doi.org/10.1016/0001-6160(82)90048-7

Risbet, M., Feaugas, X., 2008. Some comments about fatigue crack initiation in relation to cyclic slip irreversibility. Eng. Fract. Mech. 75, 3511-3519. https://doi.org/10.1016/j.engfracmech.2007.04.014

Risbet, M., Feaugas, X., Clavel, M., 2001. Study of the cyclic softening of an under-aged gamma'-precipitated nickel-base superalloy (Waspaloy). J. Phys. IV 11, Pr4-293-Pr4-301. https://doi.org/10.1051/jp4:2001436

Risbet, M., Feaugas, X., Guillemer-Neel, C., Clavel, M., 2003. Use of atomic force microscopy to quantify slip irreversibility in 
a nickel-base superalloy. Scr. Mater. 49, 533-538. https://doi.org/10.1016/S1359-6462(03)00357-9

Risbet, M., Feaugas, X., Guillemerneel, C., Clavel, M., 2009. Damage in nickel base superalloy: Influence of local parameters measured by electron backscattered diffraction and atomic force microscopy. Scr. Mater. 60, 269-272. https://doi.org/10. 1016/j.scriptamat.2008.06.053

Shin, C., Fivel, M., Verdier, M., Robertson, C., 2005. Dislocation dynamics simulations of fatigue of precipitation-hardened materials. Mater. Sci. Eng. A 400-401, 166-169. https://doi.org/10.1016/j.msea.2005.01.079

Shin, C.S., Robertson, C.F., Fivel, M.C., 2007. Fatigue in precipitation hardened materials: a three-dimensional discrete dislocation dynamics modelling of the early cycles. Philos. Mag. 87, 3657-3669. https://doi.org/10.1080/14786430701393159

Singh, V., Sundararaman, M., Chen, W., Wahi, R.P., 1991. Low-cycle fatigue behavior of NIMONIC PE16 at room temperature. Metall. Trans. A 22, 499-506. https://doi.org/10.1007/BF02656817

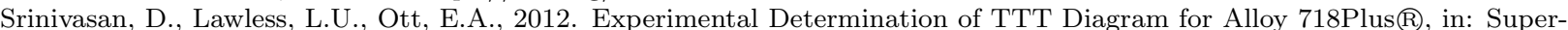
alloys 2012, Proc. Int. Symp., 12th, TMS. pp. 759-768. https://doi.org/10.1002/9781118516430.ch84

Srinivasan, V.S., Sandhya, R., Bhanu, K., Rao, S., Mannan, S.L., Raghavan, K.S., 1991. Effects of temperature on the low cycle fatigue behaviour of nitrogen alloyed type 316L stainless steel. Int. J. Fatigue 13, 471-478. https://doi.org/10.1016/ 0142-1123(91)90482-E

Stoltz, R., Pineau, A., 1978. Dislocation-precipitate interaction and cyclic stress-strain behavior of a $\gamma^{\prime}$ strengthened superalloy. Mater. Sci. Eng. 34, 275-284. https://doi.org/10.1016/0025-5416(78)90060-5

Subramanya Sarma, V., Sundararaman, M., Padmanabhan, K.A., 1998. Effect of $\gamma$ ' size on room temperature low cycle fatigue behaviour of a nickel base superalloy. Mater. Sci. Technol. 14, 669-675. https://doi.org/10.1179/mst.1998.14.7.669

Sundararaman, M., Chen, W., Singh, V., Wahi, R., 1990. TEM investigation of $\gamma^{\prime}$ free bands in nimonic PE16 under LCF loading at room temperature. Acta Metall. et Materialia 38, 1813-1822. https://doi.org/10.1016/0956-7151(90)90293-P

Sundararaman, M., Chen, W., Wahi, R., 1989. Interpretation of fatigue softening at room temperature in a superalloy. Scr. Metall. 23, 1795-1800. https://doi.org/10.1016/0036-9748(89)90363-3

Taylor, G., 1938. Plastic strain in metals. J. Inst. Met. 62, 307-324.

Turner, A.P.L., 1979. Cyclic deformation behavior of type 304 stainless steel at elevated temperature. Metall. Trans. A 10, 225-234. https://doi.org/10.1007/BF02817632.

Valsan, M., Parameswaran, P., Rao, K.B.S., Vijayalakshmi, M., Mannah, S.L., Shastry, D.H., 1992. High-temperature low-cycle fatigue behavior of a nimonic PE-16 superalloy correlation with deformation and fracture. Metall. Trans. A 23A, $1751-1768$. https://doi.org/http://dx.doi.org/10.1016/0142-1123(93)90051-Q.

Valsan, M., Sastry, D.H., sankara Rao, K.B., Mannan, S.L., 1994. Effect of strain rate on the high-temperature low-cycle fatigue properties of a nimonic PE-16 superalloy. Metall. Mater. Trans. A 25, 159-171. https://doi.org/10.1007/BF02646684

Vogel, W., Wilhelm, M., Gerold, V., 1982. Persistent slip bands in fatigued peak aged Al-Zn-Mg single crystalsI. Development of dislocation microstructure and change of precipitation distribution. Acta Metall. 30, 21-30. https://doi.org/10.1016/ 0001-6160(82)90040-2.

Wang, Z., Beyerlein, I., LeSar, R., 2008. Slip band formation and mobile dislocation density generation in high rate deformation of single fcc crystals. Philos. Mag. 88, 1321-1343. https://doi.org/10.1080/14786430802129833

Xiao, L., Chen, D., Chaturvedi, M., 2005. Shearing of $\gamma$ " precipitates and formation of planar slip bands in Inconel 718 during cyclic deformation. Scr. Mater. 52, 603-607. https://doi.org/10.1016/j.scriptamat.2004.11.023.

Xiao, L., Chen, D.L., Chaturvedi, M.C., 2008. Cyclic deformation mechanisms of precipitation-hardened Inconel 718 superalloy. Mater. Sci. Eng. A 483-484, 369-372. https://doi.org/10.1016/j.msea.2006.10.181

Yang, P., Zhou, H., 1994. Low-cycle impact fatigue of mild steel and austenitic stainless steel. Int. J. Fatigue 16, 567-570. https://doi.org/10.1016/0142-1123(94)90482-0

Yashiro, K., Kurose, F., Nakashima, Y., Kubo, K., Tomita, Y., Zbib, H., 2006. Discrete dislocation dynamics simulation of cutting of $\gamma^{\prime}$ precipitate and interfacial dislocation network in Ni-based superalloys. Int. J. Plast. 22, $713-723$. https://doi.org/10.1016/j.ijplas.2005.05.004.

Ye, D., Ping, D., Wang, Z., Xu, H., Mei, X., Xu, C., Chen, X., 2004. Low cycle fatigue behavior of nickel-based superalloy GH4145/SQ at elevated temperature. Mater. Sci. Eng. A 373, 54-64. https://doi.org/10.1016/j.msea.2004.01.045

Zecevic, M., Knezevic, M., 2015. A dislocation density based elasto-plastic self-consistent model for the prediction of cyclic deformation: Application to AA6022-T4. Int. J. Plast. 72, 200-217. https://doi.org/10.1016/j.ijplas.2015.05.018

Zhang, L., Zhao, L.G., Roy, A., Silberschmidt, V.V., McColvin, G., 2019. Low-cycle fatigue of single crystal nickel-based superalloy mechanical testing and TEM characterisation. Mater. Sci. Eng. A 744, 538-547. https://doi.org/10.1016/j. msea.2018.12.084

Zhang, P., Zhu, Q., Hu, C., Wang, C.j., Chen, G., Qin, H.y., 2015. Cyclic deformation behavior of a nickel-base superalloy under fatigue loading. Mater. Des. 69, 12-21. https://doi.org/10.1016/j.matdes.2014.12.047

Zhong, Z., Gu, Y., Yuan, Y., Yokokawa, T., Harada, H., 2012. On the low cycle fatigue behavior of a Ni-base superalloy containing high Co and Ti contents. Mater. Sci. Eng. A 552, 434-443. https://doi.org/10.1016/j.msea.2012.05.067

Zickler, G.A., Schnitzer, R., Radis, R., Hochfellner, R., Schweins, R., Stockinger, M., Leitner, H., 2009. Microstructure and mechanical properties of the superalloy ATI Allvac® 718Plus. Mater. Sci. Eng. A 523, 295-303. https://doi.org/10.1016/ j.msea.2009.06.014 